OPEN ACCESS

Edited by:

Tanima Bose,

Ludwig Maximilian University of

Munich, Germany

Reviewed by:

Anna Ermund,

University of Gothenburg, Sweden

Lei Lu,

University of Chicago, United States

${ }^{*}$ Correspondence:

Farshad Goodarzi Boroojeni

farshad.goodarzi@fu-berlin.de

Specialty section: This article was submitted to

Mucosal Immunity,

a section of the journal

Frontiers in Immunology

Received: 22 July 2021 Accepted: 07 September 2021

Published: 04 October 2021

Citation:

Duangnumsawang Y, Zentek $J$ and Goodarzi Boroojeni F (2021)

Development and Functional

Properties of Intestinal

Mucus Layer in Poultry.

Front. Immunol. 12:745849.

doi: 10.3389/fimmu.2021.745849

\section{Development and Functional Properties of Intestinal Mucus Layer in Poultry}

\author{
Yada Duangnumsawang ${ }^{1,2}$, Jürgen Zentek ${ }^{1}$ and Farshad Goodarzi Boroojeni ${ }^{1 *}$ \\ ${ }^{1}$ Institute of Animal Nutrition, Department of Veterinary Medicine, Freie Universität Berlin, Berlin, Germany, ${ }^{2}$ Faculty of \\ Veterinary Science, Prince of Songkla University, Hatyai, Songkhla, Thailand
}

Intestinal mucus plays important roles in protecting the epithelial surfaces against pathogens, supporting the colonization with commensal bacteria, maintaining an appropriate environment for digestion, as well as facilitating nutrient transport from the lumen to the underlying epithelium. The mucus layer in the poultry gut is produced and preserved by mucin-secreting goblet cells that rapidly develop and mature after hatch as a response to external stimuli including environmental factors, intestinal microbiota as well as dietary factors. The ontogenetic development of goblet cells affects the mucin composition and secretion, causing an alteration in the physicochemical properties of the mucus layer. The intestinal mucus prevents the invasion of pathogens to the epithelium by its antibacterial properties (e.g. $\beta$-defensin, lysozyme, avidin and IgA) and creates a physical barrier with the ability to protect the epithelium from pathogens. Mucosal barrier is the first line of innate defense in the gastrointestinal tract. This barrier has a selective permeability that allows small particles and nutrients passing through. The structural components and functional properties of mucins have been reviewed extensively in humans and rodents, but it seems to be neglected in poultry. This review discusses the impact of age on development of goblet cells and their mucus production with relevance for the functional characteristics of mucus layer and its protective mechanism in the chicken's intestine. Dietary factors directly and indirectly (through modification of the gut bacteria and their metabolic activities) affect goblet cell proliferation and differentiation and can be used to manipulate mucosal integrity and dynamic. However, the mode of action and mechanisms behind these effects need to be studied further. As mucins resist to digestion processes, the sloughed mucins can be utilized by bacteria in the lower part of the gut and are considered as endogenous loss of protein and energy to animal. Hydrothermal processing of poultry feed may reduce this loss by reduction in mucus shedding into the lumen. Given the significance of this loss and the lack of precise data, this matter needs to be carefully investigated in the future and the nutritional strategies reducing this loss have to be defined better.

Keywords: mucin, mucus layer, goblet cell, mucosal integrity, intestine, poultry 


\section{INTRODUCTION}

Intestinal mucus layer is the first line of defense protecting epithelium against luminal threats including mechanical forces during digestion process, enzymes and gut bacteria. The intestinal mucus also plays important roles in supporting the colonization with commensal bacteria, maintaining an appropriate environment for digestion and facilitating nutrient transport from the lumen to the underlying epithelium. The mucus layer is produced and preserved by mucinsecreting goblet cells. The present manuscript reviews the current state of knowledge about the ontogenetic development of goblet cells and the interactions between the intestinal mucus and gut microbiota as well as the mode of actions behind intestinal mucus functionality in poultry. Furthermore, it highlights dietary factors affecting goblet cell proliferation and differentiation and the consequences of these effects on mucosal integrity and dynamic in poultry.

\section{GOBLET CELL DEVELOPMENT}

Goblet cells (GC) are highly polarized columnar epithelial cells which contain secretory granules in the cytoplasm. GC secrete mucins which provide the mucosal surfaces with a thick mucus layer lining, and separate the intestinal epithelium from the luminal cavity. The mucus layer plays important roles in maintaining the intestinal microbial balance, facilitating nutrient transport, preventing pathogen invasion and regulating the microbial-host immune response (1). GC are differentiated from the transit-amplifying cells which are the transition cells between the stem cells and differentiated cells and are located in the crypts of the small and large intestine (Figure 1). The intestinal crypt is a harbor of stem cells and transit-amplifying cells which are committed to produce several cell lineages including GC and enterocytes. Maturation of the GC occur along with migrating toward the villus tip, where they are undergoing the apoptosis process or being damaged and shed into the lumen. Immature GC at the crypt base are large, pyramidal in shape, and contain mucin granules. During maturation, GC become a cup-like shape accumulating more mucin granules at the apical portion, whereas the nucleus and synthetic organelles reside at the basal portion. In chicken, the migration of GC along the villus-crypt axis occurs over a duration of 2-3 days (2).

The morphology of GC in chicken can be distinguished from enterocytes at around 16.5-18 days of embryonic age $(2,3)$. It has been shown that, the density of GC increased by 3.3 times in the duodenum from 18 to 21 days of embryonic age, whereas this number in the jejunum and ileum increased by 4.5 and 7.1 times respectively (4). However, Uni et al. (2) found no change in GC density of the duodenum during the last 3 days of incubation (2). The GC density is variable in the jejunum and ileum during the first week of age, while it is almost constant in the duodenum (2). A marked, 1.8-fold increase in the GC density was reported in the ileum during the first 4 days of age, while no significant change was observed in the duodenum (5). The GC density in the jejunum and ileum increased by approximately 1.5 and 1.8 times from day 4 to 7 of age (6). At the end of the first week post-hatch, different developmental rates of GC along the small intestine led to an anteroposterior increasing trend in its GC density, with the lowest density for the duodenum and the highest for the ileum (2, 6). The massive increase in the intestinal GC density and activity in the first week of age seems to be due to the emerging needs of newly hatched chickens for mucus secretion and immune response, associated with their immediate expose to the surrounding environment and diet. The host-related responses after hatch seem to provide enough functioning GC to maintain mucus thickness and protect the underlying epithelia from the introduced threats in the gut lumen $(6,7)$.

While the GC density in the jejunum and ileum are relatively high during the first week of age, it tends to decrease afterward

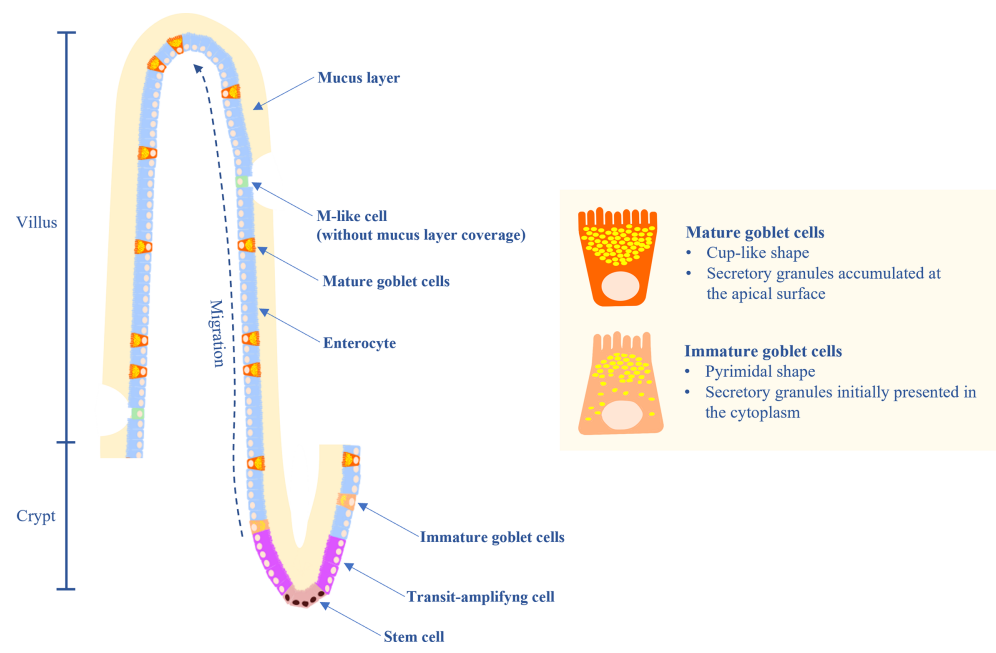

FIGURE 1 | Diagram of the small intestinal epithelium highlighting the characteristics of immature and mature goblet cells (GC), GC migration, and mucus layer. 
until the third week of life (Figure 2). The GC density tends to be stable between third and fifth week of age, with an average of 10.4 and 11.3 cells $/ 100 \mu \mathrm{m}$ of villus length in the jejunum and ileum, respectively (Figure 2). Calik and Ergün (8) also reported a stable GC density in the ileum of 21 and 42 days old chickens (14.9 vs. 13.9 cells/100 $\mu \mathrm{m}$ villus length). Therefore, although the cell renewal of GC in chickens has not been investigated yet, it can be speculated that the GC population in the small intestine may reach maturity at three weeks of age. This speculation can be supported by the outcome of several poultry studies showing an initial decline in the cell differentiation and migration rate through a decreased mitotic activity at day 21 of age compared with days 7 and $14(18,19)$.

The predominant changes in the GC density of the jejunum and ileum during the first week of age indicates that the agerelated GC development rate is region specific. The proximal part of the small intestine including duodenum is very active in digestion and absorption processes. Although GC secretion provides moisturizing and lubricant properties for epithelial cells (20), the proximal part of the intestine may prioritize the proliferation of absorptive cells over secreting cells (21), which can be associated with a lower GC density, lower mucus secretion (22) and larger GC size (23) in the duodenum compared with the jejunum and ileum. The retention time is only a few minutes in the duodenum and up to 2 hours in the ileum (24). Therefore, the lower GC density and mucus secretion in the duodenum may enhance absorptive capacity, making the duodenum accommodate to the short digesta retention time. Furthermore, the number and activity of bacteria, along with the digesta retention time, increase distally in the small intestine. The bacteria and their products are recognized by the sensor system of the intestinal and immune cells leading to an activation of the host innate defense system (25), which in turns stimulate GC differentiation via cellular signaling or secreted cytokines such as IL-1 $\beta$, IL-4, IL-13 and L-22 (1). Thus, the anteroposterior increasing trend in the GC density and mucus secretion (in the small intestine) can be assumed as a host adaptation to enhance protective barrier against the increasing number (and activity) of gut bacteria along the small intestine (25).

\section{MUCIN SECRETION}

The primary function of GC is to secrete mucins and create a protective mucus layer. Mucins are the major components in the cytoplasmic secretory granules of GC. Other proteins were also found in the GC secretion including IgA, avidin and lysozyme as well as other secretory components that play major roles in innate immunity of chicken (26). The secretion of GC is suggested to be regulated by two pathways; i) constitutive secretory pathway, and ii) regulated secretory pathway (27). The constitutive secretory pathway is a low-level continuous secretion to maintain the renewal of the intestinal mucus layer. In this baseline secretion, mucin glycoproteins are assembled and stored in membrane-bound granules which are stored within a highly organized array of microtubules and intermediate filaments called theca. The theca separates mucin granules from the rest of the cytoplasm and gives GC goblet cells a large cup-like shape (28). The constitutive secretion is dependent on cytoskeletal movement (e.g. the theca) that moves secretory granules toward the cell surface (29). This steady and unstimulated release results in maintaining the

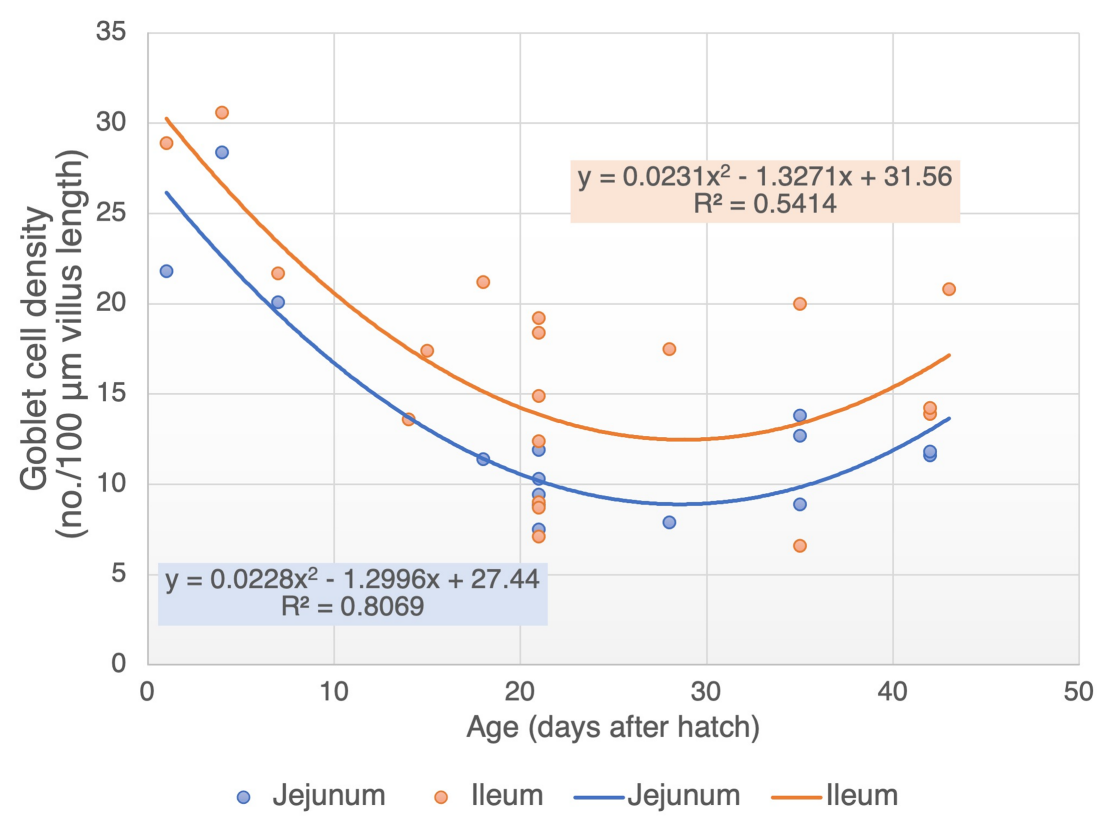

FIGURE 2 | Goblet cell density in jejunum and ileum of broiler during age development (cell number per 100 um villus length). Adapted data from references (6, 8-17). 
mucus layer (1). The regulatory pathway is an exocytosis of GC responding to external stimuli such as neurotransmitters (e.g. acetylcholine), cytokines, bacteria and their products including lipopolysaccharides (27). Acetylcholine, a primary parasympathetic neurotransmitter, plays a role in GC degranulation and can induce mucin secretion (30). Stimulation with acetylcholine or other cholinergic agonists such as carbachol resulted in a rapid transient increase in mucus secretion rates in the small and large intestine of mouse (31). Cytokine secretions by immune cells have been reported to stimulate GC proliferation and mucus production. For example, the secretion of IL-13 by dendritic cells and macrophages, IFN- $\gamma$ by the activation of Th1 pathway and IL-4, IL-5, IL-9, and IL-13 by T helper 2 have been shown to stimulate GC proliferation and mucus production (1). The presence of bacteria which disrupts mucosal surface, has been also reported to stimulate a rapid release of stored mucin granules (32). The absence of gut bacteria in germ-free chickens led to a reduction in GC number and density as well as MUC2 mRNA expression in the small intestine compared with conventional birds. These observations confirm the stimulating impact of gut bacteria on the mucin development and secretion (33). Immediate bulk release of mucins (triggered by the regulatory pathways) captures the pathogens mechanically and inhibits them chemically with antibacterial peptides/proteins (secreted by GC and other epithelial cells), while the continuous basal secretion maintains the mucus layer during an absence of luminal or physiological stimuli.

GC in chicken has some functionalities similar to Paneth cells in mammals. In mammals, Paneth cells are restricted to crypts of the small intestine and secrete substances like lysozyme, IgA, and defensins which protect host from enteric pathogens. Among these substances, lysozyme is wildly considered as a marker for Paneth cells (34). To date, presence and location of Paneth cells in the small intestine of chickens have remained controversial. An in situ hybridization analysis showed that lysozyme-positive cells were specifically located at the bottom of crypts in the small intestinal of 6-month-old chickens. These detected cells also showed morphological similarities to Paneth cells in mammal (34). However, in the small intestine of 17 days old chickens, lysozyme-positive cells were only observed in the villi epithelium and were absent in the crypts (35). In a study on the duodenum of chickens, it has been shown that lysozyme-positive cells are not only found in crypts, but can also be detected along villi. It was suggested that lysozyme-containing cells located in the small intestine villi can be either GC, goblet cells, Paneth cells, or lysozyme-positive enterocytes (26).

Mucins are synthesized and readily secreted by GC at the crypt, while their compositions and secretion rate change along with cell migration. During migration of GC from the crypt, the mucin secretion and renewal rate increase (22) and the oligosaccharide chains in the mucin glycans are elongated by the addition of monosaccharides (36). The elongation of mucin glycans and higher secretion of mucin may indicate the maturation of GC along the migration toward the villus tip. In a mice study, it has been shown that, the duration of mucin synthesis is around 3-4 hours in the crypts and less than 3 hours in the villi (22). A faster mucin production and secretion by GC at the villi compared with crypts may be a physiological response to facilitate luminal mobility and digestion as well as protect the villi surface against mechanical erosion and microbial invasion (22), while the preserved mucins at the crypt can provide a further protection by a massive release in case of gut inflammation and infection (37).

A well-developed mucus layer in the gut is important for an active immunity system. Beside mucin secretion, the gut GC also participate in the immune responses by secretion of various substances acting as antibacterial agents. GC in the duodenum and cecum of broilers were shown to store avidin, lysozyme and other secretory components (26). Avidin was found to be an acute phase protein which is expressed in the intestine during gut injury and inflammation (38) and involves in restoration of a damaged intestinal tissue (39). Secretory components like cleaved fragments of $\mathrm{pIgR}$, have neutralizing properties against pathogen-associated molecules and act as antibacterial substances (26). Lysozyme plays an important role in activating innate immunity and recruiting of leukocytes (26). Immune protection of the gut in early life stage depends on provision of maternal antibodies including IgA, IgG and IgM which can be delivered via colostrum and milk in most of mammals (40). However, industrial avian species have no direct contact with parents after the egg is laid; hence, the only source to supply maternal antibody is the egg itself. Maternally derived IgA was found in the GC and epithelial apical surface of newly hatched chickens. Maternally derived IgY (the avian counterpart to mammalian IgG) was observed in the intestinal vessels at the day of hatch. Both Ig appeared later (7-28 days of age) in the plasma cells located in the lamina propria of the small intestine (41). The GC seems to act as a reservoir for maternal IgA antibodies prior to hatch which are slowly secreted along with mucin, thus extend the protection until maturation of the endogenous IgA response (41). During the first week after hatch the maternal IgA in chickens decreases gradually and the maturing antibody secreting cells subsequently take over the immunological protection (7).

\section{MUCIN CHARACTERISTICS AND GOBLET CELLS CATEGORIZATION}

Structurally, mucins are large glycoproteins characterized by heavily $O$-glycosylated polypeptides that usually composed of tandem repeats rich in proline, threonine and/or serine sequence (PTS domain). The hydroxyl group of threonine and serine is necessary for ester linkages between the amino acid backbone and carbohydrate groups (42). A dense array of $O$-linked carbohydrates in mucins confers charge to them, giving them the ability to interact with other surrounding molecules such as nutrients and regulate the diffusion of nutrients within the mucus layer. Mucin O-glycans account for over $80 \%$ of the total mucin molecule by mass and support rigidity of the mucin structure, contributing to specific physical and biological properties essential for their protective functions 
(43). For instance, the chicken MUC2 mucin comprises 3,697 amino acids (44) and >100 different Oglycan structures linked to the mucin protein core (45). Mucin O-glycans typically contain several types of sugars (Figure 3) including $\mathrm{N}$-acetylglucosamine (GluNac), N- acetylgalactosamine (GalNac), galactose, sialic acid, fucose and mannose (46-48). The glycan biosynthesis begins by the transfer of one sugar to the protein, followed by the addition of more monosaccharides one by one (32). In chicken, $\mathrm{O}$-glycans are predominantly composed of GlcNAc, galactose and GalNAc at approximately 37.0, 27.4 and $13.4 \%$, respectively, while the remaining includes sialic acid, fucose and mannose (46). Further structural diversity is obtained through modifications of the saccharides e.g. phosphorylation, sulfation, and acetylation (32). The most common terminal end of glycans in the small and large intestine of chicken contains sulfated and sialylated groups which account for the polyanionic or negative charges of mucins (49). The complexity of mucin carbohydrate structures is regulated by glycosylation within the Golgi apparatus of the GC. The pattern of monosaccharide sequence in mucins varies between individual GC, intestinal location and species (32).

Depending on the ionic charge of the mucin molecule, mucins can be differentiated (Table 1) as neutral or acidic (50). The $O$-glycans containing terminal residues of sialic acid and sulfated group represent anionic charge, while other terminal groups such as fucose, hexose and galactose result in neutral charge. The negatively charged mucins are likely to resist mucin degradation by bacterial enzymes therefore; mucin charge is an important factor in determining host defense with particular regard to interactions with microorganisms present in the gut. It is noteworthy that the $O$-glycosylation occurring in the GC is usually very heterogeneous and not only a single type of mucin is produced in an individual GC (50). Based on the sum of ionic charge of secreted mucins, GC can also be categorized into two types; 1) neutral GC predominated by neutral charged mucins and 2) acidic GC predominated by anionic charged mucins (Table 1). By using common microscopic observations in histological studies, staining of secretory granules in GC represents a color as the result of a chemical reaction between dyes and the terminal groups of mucins. The anionic mucins can be detected by cationic dye including Alcian blue $(\mathrm{AB})$ and mucicarmine resulting in blue and red in color, respectively (51). In contrast, the neutral mucins can be recognized by the reaction between Periodic acid -Schiff (PAS) reagent and aldehyde groups of the monosaccharide units, resulting in magenta color (51). GC containing almost similar amount of acidic and neutral mucins appear in bluish purple color and are called mixed GC (52). In chicken, the mixed GC are commonly observed along the small intestine $(53,54)$. Most of the studies conducted on chicken have used both $\mathrm{AB}$ and PAS solutions for mucin determination in the gut tissue, individually or together (combined staining method). The individual staining method uses only one solution at the time for each tissue sample (determining acidic and neutral GC in separate tissue samples), while the combined staining method

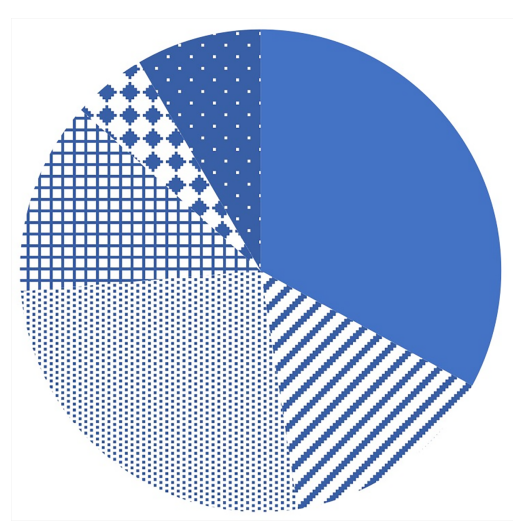

- N-acetylglucosamine (GluNAc)

$\leftarrow \mathrm{N}$-acetylgalactosamine (GalNAc)

: Galactose

H Sialic acid

Mannose

Fucose

FIGURE 3 | Proportion of mucin monosaccharides in the small intestine of broiler $(46,47)$.

TABLE 1 | Characteristics of neutral and acidic goblet cells ${ }^{\text {a }}$.

Mucin structure

Mucin O-glycan

composition

Terminal end of 0 -

glycan

The overall charge

of mucins

Large glycoproteins containing extensive amounts of oligosaccharide chains attached to protein core

Heterogenous arrangement of monosaccharides including GluNAc, GalNAc, galactose, fucose, sialic acid and mannose

Predominant in neutral charged monosaccharides e.g. GluNAc, GalNAc, galactose, fucose and mannose

Neutral charge
Predominant in negatively charged monosaccharides e.g. sialic acid and/or sulfated groups

Negative charge

areferences (49-52). 
uses both solutions in one process (determining acidic and neutral GC in one tissue sample). Given the fact that one GC can produce more than one type of mucin (2), overestimation of acidic and neutral GC number may be more likely to happen by using the individual staining method. Therefore, the histochemical technique of "combined staining method" may be more accurate to define the GC types.

Mucins are also broadly grouped into transmembrane and secretory mucins based on their biosynthesis and secretion. The secretory mucins are initially formed by mucin polymers and packed into secretory granules prior secretion (55). Upon mucin granule exocytosis, the secretory mucins are hydrated and expanded massively, forming a gel-like structure and creating a mucus layer over the intestinal epithelium. The transmembrane mucins are characterized by a single transmembrane protein incorporated into the plasma membrane, a cytoplasmic tail (signaling domain) and the extracellular part of a highly glycosylated mucin domain. These mucins are retained at the apical cell surface of GC (55). The transmembrane mucins do not form gel-like structure but rather serve as anchors for the secretory mucins. However, the strict classification of both mucin types is complicated by their dual occurrence of membrane attachment and detachment; the transmembrane mucins can be forced to detach from the cell surface by mechanical stimuli (56), while the secretory mucins temporarily attached to the apical surface of GC prior the cleavage by proteolytic enzymes (1). Proteolytic enzymes such as Meprin $\beta$ are likely to cleavage the specific site at the anchor point between secretory mucins and cell membrane. This cleavage is found to be activated through bacterial contact or microbial signaling to the enterocytes, indicating that the presence of gut bacteria may be a key mechanism for secretory mucin detachment and release into the intestinal lumen (57). It has been observed that Meprin $\beta$ was deficient in the small intestine of germ free mice resulting in less viscous mucus layer, thus more adhesive and attached mucus to the cell membrane (57).

Mucins are encoded by mucin genes, represented as MUC followed by a number that reflects the order in which the particular mucin gene was discovered. A mucin gene is translated into a protein core which is further decorated with extensive glycosylation. The discovered MUC genes in chicken are still limited compared with human (Table 2). Different types of mucin are present throughout the gastrointestinal tract in specific locations. Each type plays a different role in maintaining homeostasis and protecting intestinal epithelium in different parts of the gut. In chicken, the MUC2 is the major component of mucus in the small and large intestine but it is weakly expressed in the crop (44), whereas MUC5ac is specifically expressed in the proventriculus and only weakly expressed in the small intestine $(6,45)$. The composition and sequence of amino acids derived by specific MUC genes have a role in dimerization through covalent and noncovalent crosslinks and their subsequent polymerization to form multimers $(61,62)$. The structure conformation of different MUC type mucins (such as MUC2 vs. MUC5ac) was found to differ in cross-linking between mucin dimers, which may determine their functionality in regard to mucus permeability (61) and viscosity (62) in different parts of the gastrointestinal tract. The tissue specific expression of MUC genes seems to be depending on the physicochemical properties of the mucins and their required functionality in maintaining mucosal integrity in that specific part of the gut.

\section{DEVELOPMENT OF ACIDIC AND NEUTRAL MUCINS}

The physiological relevance of distinct mucin types is not yet well understood but it has been suggested to be associated with their protective properties. The distribution of mucin types in the GC is regulated by glycosylation process, which can be affected by host (e.g. inflammatory markers, hormones and neurotransmitters) and external (e.g. commensal bacteria, pathogens, pre/probiotics and nutrients in the diet) factors (20). It is known that many bacteria in the gut produce glycosidases or proteases to degrade mucus. The terminal ends of $\mathrm{O}$-glycan with $\mathrm{O}$-acetylated sialic acid (sialomucins) or

TABLE 2 | Mucin genes expressed in the small and large intestine of human and chicken.

\begin{tabular}{|c|c|c|c|c|}
\hline \multirow[t]{2}{*}{ Mucin types } & \multicolumn{2}{|c|}{ Human $^{a}$} & \multicolumn{2}{|c|}{ Chicken $^{b}$} \\
\hline & Small intestine & Large intestine & Small intestine & Large intestine \\
\hline \multirow[t]{8}{*}{ Transmembrane mucins } & MUC1 & MUC1 & MUC4 & $\mathrm{n} / \mathrm{a}$ \\
\hline & MUC3 & MUC3 & MUC13 & \\
\hline & MUC4 & MUC4 & & \\
\hline & MUC12 & MUC12 & & \\
\hline & MUC13 & MUC13 & & \\
\hline & MUC15 & MUC15 & & \\
\hline & MUC16 & MUC17 & & \\
\hline & MUC17 & & & \\
\hline \multirow[t]{3}{*}{ Secretory mucins } & MUC2 & MUC2 & MUC2 & MUC2 \\
\hline & MUC5ac & MUC5b & MUC5ac & MUC6 \\
\hline & MUC6 & & & \\
\hline
\end{tabular}

n/a, no available data.

areferences $(56,58)$.

${ }^{b}$ references $(59,60)$. 
sulfated group (sulfomucins) have been found to play a key role to protect mucin chains from degradation by bacterial enzymes (like proteases and glycosidases) and proteolytic host enzymes $(52,63)$. Previous studies on the chicken's intestinal mucosal layer and mucin subtypes indicate that during late embryonic development, the produced mucins are more of the acidic subtype than neutral subtype $(2,4,64)$. It seems that acidic mucins production prevails before hatch and then neutral mucins are more produced after hatch (6). In newly hatched chicks, the density of acidic and neutral GC was increased during the first week of age in the small intestine, especially in the jejunum and ileum. This increase was suggested to be due to the bacterial colonization in the gut and presence of dietary components $(6,7)$. The dominance of acidic mucin production by GC right before hatch could be a host adaptation to proteolytic host enzymes (to use yolk sac) and prepare the chicken for exposure to bacterial proteases and glycosidases right after hatch (2).

The development of sialomucins and sulfomucins from late embryonic stage to post-hatch is shown in the Table 3. Sulfomucins appear initially as early as 18 days of embryonic age (4), while mucins containing sialic acids appear later at 21 days of embryonic age and considerably increase after hatch, especially during the first week of age $(4,6)$. The high amount of sulfomucins presented at embryonic stage may be due to the immaturity of GC (because of the low number and activity of gut bacteria) (6). No exposure of hatching eggs to the caecal content of the layers caused a reduction in the number of both neutral and acidic GC with the absence of sialomucins during the first 7 days of age, compared with the chickens hatched from conventional eggs (33). The presence of intestinal bacteria could induce GC maturation and increase mucus production which could associate with increasing amount of sialomucins after hatch (6). It was found that GC initially contain higher amount of sulfomucins and lower amount sialomucins, but as they mature and migrate toward the villus tip, the mucins are increasingly sialylated (63). This can indicate the importance of bacterial exposure for GC differentiation and maturation (33).

\section{MUCUS LAYER AND ITS THICKNESS}

The thickness of mucus layer is a result of dynamic balance between secretion rate by GC and destruction rate through mechanical shear and enzymatic degradation (66). During a normal physiological condition, the mucus thickness is determined by the basal secretion which involves the continuous production and release of mucins into the gut lumen as previously discussed. Two methods have been applied to measure mucus thickness from the basal secretion. One is by using cryostat-sectioned tissue stained with histochemical staining (CRHS) and the other is by using anesthetized animal (in vivo). The CRHS method is a simple method that can be used for a wide range of tissue types and can show the characterization of normal mucus layer. The in vivo method provides information about the dynamic of mucus secretion under a real physiological regulation (67).

By microscopic observation, it has been shown that the intestinal mucus consists of 2 layers; i) a thin inner layer which is strictly attached to the epithelial membrane ii) a thick outer layer which is loose, non-attached and forming viscous gel between the lumen and the thin inner layer (68). It can be expected that the inner layer contains transmembrane mucins because it was hardly removed by mucolytic agents (69), while the outer layer may contain secretory mucins which form a viscous mucus layer (1). In human and rodent, mucus in the small and large intestine have both layers, while the inner layer of the small intestine is thinner than the large intestine. However, several studies in both species showed that the inner layer was absent in the small intestine, especially in the duodenum and jejunum $(56,70)$. It seems that generally, the thickness of mucus is higher in the distal part (caecum $>$ ileum $>$ duodenum and

TABLE 3 | Percentage of acidic goblet cell number in the jejunum and ileum of broiler at different ages.

\begin{tabular}{|c|c|c|c|c|c|}
\hline \multirow[t]{2}{*}{ Intestinal part } & \multirow[t]{2}{*}{ Age $^{a}$} & \multicolumn{3}{|c|}{ Percentage of acidic goblet cell number ${ }^{b}$} & \multirow[t]{2}{*}{ Reference } \\
\hline & & Sialomucin & Sulfomucin & Intermediate & \\
\hline \multirow[t]{7}{*}{ Jejunum } & E18 & - & $100 \%$ & - & (4) \\
\hline & E21 & $20 \%$ & $56 \%$ & $24 \%$ & (4) \\
\hline & D1 & - & $100 \%$ & - & (6) \\
\hline & D4 & $31 \%$ & $38 \%$ & $38 \%$ & (6) \\
\hline & D7 & $18 \%$ & $41 \%$ & $41 \%$ & (6) \\
\hline & D18 & $34 \%$ & $49 \%$ & $17 \%$ & (65) \\
\hline & D18 & $30 \%$ & $54 \%$ & $16 \%$ & $(10)$ \\
\hline \multirow[t]{6}{*}{ Ileum } & E18 & - & $100 \%$ & - & (4) \\
\hline & E21 & $37 \%$ & $18 \%$ & $45 \%$ & (4) \\
\hline & D1 & - & $100 \%$ & - & (6) \\
\hline & D4 & $28 \%$ & $39 \%$ & $39 \%$ & (6) \\
\hline & D7 & $28 \%$ & $39 \%$ & $33 \%$ & (6) \\
\hline & D18 & $33 \%$ & $47 \%$ & $20 \%$ & (10) \\
\hline
\end{tabular}

${ }^{a}$ Age was reported as days of embryo age (E) or chicken age (D).

${ }^{b}$ Acidic goblet cell was determined by the combined staining Alcian Blue/High Iron Diamine (AB/HID) method. AB-positive goblet cells (blue) are categorized as sialomucin, HID-positive goblet cells (brown) are categorized as sulfomucin, and goblet cells that are positive to both AB and HID stains (brown-black color) are called intermediate. The percentage of each type is relative to the total number of acidic goblet cells (the sum of sialomucin, sulfomucin and intermediate). 
jejunum) of the intestine (68), which may be explained by the digestive and protective functions of mucus and the fact that, gut bacterial number and activity increase from the proximal part of the small intestine to the distal part of the gut. Few studies measured the mucus thickness in chicken by the histological method. The average of mucus thickness in 42 days old broilers ranged from $14.9 \mu \mathrm{m}$ in the duodenum to $18.6 \mu \mathrm{m}$ in the ileum $(46,47)$. In a CRHS study using anesthetized rats, the basal mucus secretion rate was the highest in the colon $(3.9-5.2 \mu \mathrm{m} /$ $\mathrm{min})$, while the secretion in the small intestine ranged from 1.9 to $4.7 \mu \mathrm{m} / \mathrm{min}$, with the highest rate in the ileum compared with duodenum and jejunum (68). Furthermore, it has been shown that by removing mucus layer with a suction probe, the inner mucus layer remained attached to the mucosal surface, while the outer layer in all parts of the gut was easily removed by suction collection. The mucus secretion was immediately stimulated after the mucus suction, with a lower secretion rate in the small intestine and a higher rate in the colon compared with those prior mucus removal (68). Thus, the mucus layer at the lower part of the gut seems to be better maintained resulting in a thicker mucus layer covering the epithelial surface of the colon.

\section{NUTRIENT TRANSPORT THROUGH MUCUS LAYER}

The intestinal mucus must provide a robust barrier that traps and immobilizes potentially hazardous compounds such as pathogens, while allowing the passage of nutrients to the epithelial surfaces. These properties are particularly important in the small intestine, where the mucus layer is the thinnest in the gut and the nutrients absorption needs to be highest. A thinner mucus layer in the small intestine could facilitate nutrient absorption, whereas a thicker mucus layer in the colon must be a barrier to the dense bacterial population (71). Since more than $90 \%$ of the total nutrients absorption including carbohydrates, proteins and lipids occur in the small intestine (72), the mucus properties involved in nutrient diffusion are of interest. It has been reviewed by Leal et al. (72) that physiochemical properties of mucus like pore size, viscoelasticity, $\mathrm{pH}$, ionic strength, and net charge of mucus layer and mucin polymers can alter the transportation of molecules (Table 4) (72). They suggested that these factors regulate permeability of mucus layer which not only restrict the diffusion of bacteria and macromolecules but selectively, allow absorption of nutrients (72).
The net-like structure of mucus layer creates pores which allow only small molecules from the lumen pass through the mucus layer and restrict the flow of large molecules including polysaccharides and polypeptides (1). Limited studies evaluated the pore size of the intestinal mucus but it is known that the mucin network expands 2-3 times in volume when moving from the inner layer to the outer one (1). Several studies reported that particle size ranged from $0.5-2 \mu \mathrm{m}$ in diameter could diffuse through the outer mucus layer of the jejunum (73) and ileum (70), while the inner mucus layer are sufficiently small $(<0.5 \mu \mathrm{m}$ diameter) to hinder penetration of bacteria or beads (1).

The viscosity of mucus layer is attributed to the capacity of mucin monomers to form polymeric structures. Only the secretory mucins are properly assembled into a disulfidebridged covalent network, giving mucus its viscous properties, while transmembrane mucins are monomers that are integrated into membranes and do not form viscous gels. The viscosity of the mucus ranged from 1 to 30,000 millipascal second along the villus surface of the pig's small intestine, with a numerically higher mean viscosity at the inter-villus space (the space between the villi) compared with the villus tip (73). In general, a low viscous mucus provides a higher permeability for diffusing molecules (74), thus the diverse viscosity at different part of the villi may indicate the preferential area for nutrient diffusion. However, diffusion of particles through mucus layer was greater at the inter-villus space compared with villus tip due to a hindrance of the apoptotic cells that shed into the mucus (73).

Different components in the mucus such as water, mucins, globular proteins, salts, DNA, lipids, cells and cellular debris are stabilized by covalent and noncovalent interactions including hydrophobic, electrostatic and hydrogen bonds (72). These binding interactions are the main factors that contribute to viscoelasticity and permeability of a mucus layer (72). Generally, charged groups of the mucins can interact with charged particles and immobilize them through the mucus (74). Peptides which contain both basic and acidic amino acids have both positive and negative charges simultaneously. It was found that when positive and negative charges were both present on a peptide, the diffusion through gastric mucins was higher than the isolated charged peptides (75). The interaction between charged particles and mucins also rely upon the intestine's $\mathrm{pH}$ as well as ionic strength of the intestinal mucus (74). Lowering the mucus $\mathrm{pH}$ altered mucus conformation by promoting the exposure of hydrophobic domains of the mucins, decreasing repulsive forces between mucins and increasing mucus viscosity (72). Thus, a reduced electrostatic interaction between mucins

TABLE 4 | Physiochemical characteristics of mucus layer affect nutrient transportation ${ }^{\text {a }}$.

\begin{tabular}{|c|c|}
\hline Characteristics & Impact on nutrient transportation \\
\hline Pore size & Size-filtering property \\
\hline Viscoelasticity & Lower mucus viscosity provides a higher permeability for diffusing molecules \\
\hline $\mathrm{pH}$ & Higher pH increases electrostatic interaction between mucins which enhances selective permeability of charged particles \\
\hline lonic strength & Higher ion concentration enhances permeability of positively charged molecules \\
\hline Net charge & Attractive or repulsive forces between diffusing molecules and the mucus \\
\hline
\end{tabular}

areferences (72-76). 
enhances selective permeability against charged particles compared with neutral particles (72). In porcine gastric mucins with $\mathrm{pH}$ adjustment to 3 , the positive and negative charged polyethylene glycols (PEG) were less mobile leading to low diffusion, while both charged and neutral particles diffused almost freely in mucus at $\mathrm{pH} 7$ (74). The $\mathrm{pH}$ limitation for nutrient diffusion through mucus layer may be lesser in the distal part of the small intestine compared with the proximal part because of the fact that in chicken, $\mathrm{pH}$ increases from the duodenum (5.0-6.0) to the jejunum (6.5-7.0) and ileum (7.07.5) (76).

Changes in ionic strength cause shrinkage or swelling of mucus and, thus, significantly alter mucus viscoelasticity (77). The strength of the attractive or repulsive forces between mucin molecules depends on the ion content in the mucus layer including sodium, chloride, potassium and calcium ions (74, 78). In general, increases in ion concentration correlate with a decrease in the viscosity of mucus (77). The investigation of ionic strength in the intestinal mucus layer of chicken has not been yet explored. Using porcine gastric mucus (ex vivo), it was demonstrated that the mobility of positively charged particles was considerably increased at high ionic strength $(500 \mathrm{mM} \mathrm{NaCl}$, $\mathrm{pH} 3)$ compared with low ionic strength conditions $(20 \mathrm{mM}$ $\mathrm{NaCl}, \mathrm{pH} 3$ ), while neutral particles diffusivity remained unaffected by changes in the ionic strength (74). Similarly, increasing the ionic strength $(5-200 \mathrm{mM} \mathrm{NaCl}, \mathrm{pH}$ 7) of porcine gastric mucus accelerated the transport rate of cationic peptides (lysine residue), while the anionic peptides (glutamic acid residue) maintained a high diffusion at various ionic strengths (75). Therefore, it can be speculated that that high ionic strength of mucus layer in a neutral $\mathrm{pH}$ condition, which usually occurs in the lower part of the small intestine (compared with the proximal part of the gut), may lead to a higher permeability of positively charged molecules in this part of the gut.

\section{PROTECTIVE MUCUS LAYER AGAINST GUT BACTERIA}

The intestinal mucus layer provides a protective shield for epithelium against gut microbiota which begins to colonize within an hour after hatch (79). The bacterial colonization was initially observed in the cecum, possibly because of yolk sac utilization and absorption effect, which was dominated by facultative aerobes such as Enterobacteriaceae and Streptococcus spp. and then spread throughout the gastrointestinal tract within 24 hours $(79,80)$. It has been reported that the bacterial concentration increases distally along the small intestine due to increasing luminal $\mathrm{pH}$ and retention time in the distal ileum compared with the duodenum (79). Approximately one third of the commensal bacteria is comprised of genes involved in carbohydrate digestion and many bacteria have specialized genes for degrading different type of complex carbohydrates such as non-starch polysaccharides (81). In a normal condition, gut bacteria locate only in the outer mucus layer where they can degrade mucin glycans or proteins and utilize them as energy source for colonization, while the inner layer is relatively impermeable for bacteria (82). However, when the mucosal barrier function is disrupted, the mucus becomes more permeable and a higher number of bacteria can be found in the inner layers (82). A more invasive bacteria including pathogens may extensively degrade mucins and compete with the gut microflora for mucin-derived nutrients, establishing their colonization and epithelial attack.

The homeostasis of gut bacteria in chicken can be affected by mucin (MUC) types, O-glycan composition (extent of glycosylation and oligomerization of mucin), and the mucus layers characteristics (inner and outer mucus layer thickness) (50, 83). Mucin types and O-glycan composition affect physicochemical properties of mucins and the effectiveness of bacteria for reaching epithelial cells by degradation of mucins (50). Several mechanisms for the intestinal mucus were reported which prevent the invasion of pathogens, while maintaining a homeostatic microbial population. The continuous secretion of mucus pushes the pathogens away from the enterocytes and flushes them out distally with peristaltic moves (73). Moreover, antibacterial peptides and proteins within the mucus prevent a direct access of bacteria to the epithelial surface. In chickens, antibacterial compounds in GC secretion including $\beta$-defensin, lysozyme, avidin, IgA, and free secretory component (a glycoprotein that binds and transports the secretory immunoglobulins) were found as responses to both gram positive and negative bacteria (26). The continuous secretion of these peptides and proteins creates an antibacterial gradient within the mucus layer with an increasing antibacterial activity from the lumen to the cell surface, creating stricter protection at a closer area to the epithelium (56). Due to a shielding or charge repulsive effect of the anionic glycans, the interaction between mucins and pathogens could also slow down their penetration. A high abundance of sulfated and sialylated mucins could reduce the adhesion and penetration ability of Campylobacter jejuni through intestinal mucus of chicken and protects the mucins from degradation by bacterial glycosidases (84). The protective properties of mucus may also rely on mucin subtypes (e.g. MUC2 and MUC5ac) through the interaction between protein domains which as discussed, can determine the permeability of the mucus layer $(25,61)$.

Although the small intestine contains lower bacterial population than the lower gut, it may be a better target for pathogenic bacteria due to its thin and patchy distributed mucus layer. Furthermore, a particular area in the small intestine lacks of mucus coverage (Figure 1). This area composes of M-like cells overlying on the lymphoid tissues of the digestive tract and bursa of Fabricius (32). The M-like cells act as sentinel cells which transport endocytosed microorganisms and other antigenic substances into the underlying lymphoid structures and initiates immune response. However, some bacteria including Salmonella Typhimurium, Shigella flexneri, Yersinia enterocolitica and Vibrio cholerae take advantage of the low protective barrier of this area and invade the epithelial cells (32). 
Intestinal mucus not only serves as a protective layer but also accommodates the colonization of bacteria by providing i) ligands for bacterial adhesion, and ii) nutrient sources for selective bacterial community that contains mucin degrading enzymes or receives degraded mucin saccharides from the others (83). The colonization ability of bacteria depends on the bacterial attachment, bacterial enzymes for mucin degradation and utilization capacity of them for mucin-derived carbohydrate. These mechanisms were extensively reviewed by Sicard et al. (83). The bacterial adhesion to mucins is believed to initiate the colonization process which involves one or more mechanisms including Van der Waals forces, electrostatic interaction, and hydrophobic forces (85). Bacteria frequently use different strategies like cell-surface proteins, pili, fimbriae and flagella to bind to mucins (83). Some commensal bacteria including lactic acid bacteria occupy mucus binding proteins and pili to adhere to mucin oligosaccharide (e.g. mannose), while other adhesion strategies were observed for pathogenic bacteria. For example, $C$. jejuni uses the carbohydrate-lectin, flagella subunit proteins and major outer membrane proteins to adhere to mucins (83).

Mucolytic bacteria possess specific enzymatic activity necessary to degrade glycan chains and facilitate their colonization. Their enzymes include neuraminidases/sialidases, fucosidases, exo- and endo- $\beta$ - $\mathrm{N}$-acetylglucosaminidases, $\beta$-galactosidases, $\alpha-\mathrm{N}$-acetylglucosaminidase, and $\alpha$-N-acetylgalactosaminidases (86). The members of mucolytic bacteria are groups from both commensal (such as Bifidobacterium bifidum, Bacteroides fragilis, Akkermansia muciniphila) and pathogenic bacteria (such as Clostridium perfringens, Salmonella Typhimurium, Vibrio cholerae, Enterococcus faecalis). These bacteria compete for mucinderived nutrients (86). Some of the intestinal pathogens have developed strategies to win this competition with commensal microflora for nutrients. It has been found that Clostridium perfringens have developed an ability to secrete a wide range of glycosidases with broader substrate specificity (87). Clostridium perfringens has shown a wide range of enzymatic activity in cleaving the terminal residues (exoglycosidases) and inner parts of sugar chains (endoglycosidases) including $\alpha$-L-fucosidases, endo- $\alpha$-GalNAcase and sulfatases, which promote adherence to the mucin carbohydrate receptors and mucin degradation (43). Therefore, a broader range of substrates is available for Clostridium perfringens which increases their chance to win the competition and cause necrotic enteritis in poultry. Another set of gut bacteria without mucolytic activity can also take advantage of released saccharides by scavenging the liberated sugars, leading to an increased in their colonization in the gut. For example, the presence of $B$. thetaiotaomicron or $B$. fragilis that produce sialidases enabled the expansion of sialic acidscavenging bacteria including E.coli (88).

It has been shown that the common modification of terminal glycans of human mucins including sulfation and sialylation, increases resistance to microbial glycosidases and thus, the protective barrier is thought to remain more intact $(6,86)$. The 5increase in anionic (sialytated, sulfated and sialytatedsulfated) glycans was also reported in chicken and other avian species as a strategy to provide a charge-repulsion effect between mucins and maintain relatively low $\mathrm{pH}$ of mucins, aiming to create strong protection for mucins against bacterial degradation (84). In chicken, the $O$-glycans were abundantly sulfated and sialylated, with $33 \%$ and $23 \%$ in the jejunum and $34 \%$ and $29 \%$ in the cecum, respectively, while the remaining was neutral glycans $(40 \%$ and $26 \%$ ) and sulfo-sialylated intermediate (4\% and $11 \%)$ in the respective locations (84). However, some bacteria possess strong sialidase and/or sulfatase activity. For example, Ruminococcus gnavus and Akkermansia muciniphila have sialidase activity, while Prevotella spp., Bifidobacterium spp. and Helicobacter pylori have sulfatase activity (86). Some bacteria produce both enzymes such as Bacteroides fragilis, $B$. thetaiotaomicron and Bifidobacterium bifidum $(86,88)$. Among bacteria with sialidase activity, the released sialic acid can be only utilized by some groups like $R$. gnavus and $B$. fragilis since they are the ones encoding specific genes responsible for sialic acid metabolism. On the other hand, Salmonella Typhimurium and Clostridioides difficile are able to utilize sialic acid but lack the sialidase enzyme, and thus, they rely on other sialidase-producing organisms to acquire this potential nutrient source $(86,88)$.

\section{ENDOGENOUS LOSS OF MUCUS LAYER}

Mucus degradation generally occurs due to physical disruption by mechanical shear forces of peristalsis and enzymatic cleavage by bacteria, after which the mucus is transported with the intestinal content and excreted (20). Broilers have a short intestinal retention time to support a high feed intake despite the limitations of the digestive tract volume. The average retention time in broilers is 2.9 and 5.7 hours for the small intestine and total tract, respectively (24). Furthermore, chicken has a unique mechanism of intestinal reflux that propel liquid material from the proximal ileum or cloaca ascendingly to as far as the duodenum and gizzard in order to enhance digestibility of major nutrients such as starch (89). The high passage rate and frequent intestinal movement in chicken may contribute more to loss of the mucus layer compared with other species. It is noteworthy that the outer mucus layer is more loose and prone to be propelled with digesta transportation compared with the inner layer (68). Hydrothermally processed diets such as pelleted, extruded and expanded, feed may provide low mechanical shear force due to the rapid disintegration once moistened (90). Moreover, these forms of feed have higher starch digestibility compared with the non-processed one (91), reducing the need for frequent intestinal reflux to enhance digestibility of starch. It has been shown that pelleted feed increased villus height, decreased crypt depth and GC density in the small intestine of broilers compared with mash feed (92). It can be assumed that higher GC density in broilers fed mash feed is an adaptive response to increase mucin secretion and replace the part of the mucins which has been lost due to enzymatic hydrolysis, mechanical shear forces or intestinal refluxes. Thus, hydrothermal processing of poultry feed may reduce mucus shedding into the lumen. 
To our best knowledge, the direct effect of particle size (fine/ coarse) on mucins secretion in poultry has not been investigated yet. The coarse and fine feed are usually characterized by discrete mean particle size (dMEAN) based on dry sieving analysis; dMEAN above and below $1.8 \mathrm{~mm}$ are defined as coarse and fine particle sizes, respectively (93). It is generally believed that fine particles increased the accessibility of digestive enzymes to the substrate and enhance nutrient digestibility (90). However, some studies have shown that reduction in particle size of cereals (e.g. corn) did not affect ileal digestibility of amino acids that are accounted for more than $50 \%$ of the amino acid content of each type of mucin i.e. glutamic acid, aspartic acid, proline, threonine and serine (93) as well as crude protein $(94,95)$. Other studies showed a lower ileal digestibility of crude protein in fine corn compared with coarse corn $(96,97)$. It was suggested that finely ground particles may cause gut functional impairment due to a faster passage rate (98), while coarse particles reduce passage rate and enhance gizzard activity which may subsequently stimulate more bile acid and pancreatic secretion and also improve digestibility of nutrients like starch $(91,99)$. The dietary replacement of fine corn $(2.4 \mathrm{~mm})$ with coarse corn $(7.16 \mathrm{~mm})$ by $25 \%$ or $50 \%$ in pelleted feed increased digesta retention time, gizzard weight, and apparent ileal digestibility of energy and nitrogen, while the digesta $\mathrm{pH}$ seemed to be decreased in the proventriculus (100). The lower $\mathrm{pH}$ of the digesta entering duodenum may enhance mucus degradation by enzymatic hydrolysis (101) and may increase mucus secretion in response to prevent epithelial damage (102). In terms of nutrients absorption, the lower $\mathrm{pH}$ of the digesta entering duodenum can increase mucosal viscosity which as discussed, subsequently may cause lower permeability for certain nutrients. Furthermore, replacing fine particles with coarse ones could increase intestinal muscle (tensile strength) activity (100) which on one hand, may increase mechanical shear force between luminal materials and intestinal mucosa, enhancing mucus loss into the lumen and on the other hand, increases retention time of digesta leading to a higher nutrient digestibility and subsequently less intestinal reflux and loss of the mucus layer.

Mucins are high molecular mass $\left(2 \times 10^{6} \mathrm{Da}\right)$ of heavily $O$-glycosylated polypeptides which resist to digestive processes resulting in a significant fraction of endogenous losses (103). The endogenous loss of mucin carbohydrates and amino acids are commonly determined at the end of ileum instead of total tract because of the variable and modifying effects of the hindgut microbiome on nutrient utilization (104). The quantification of mucins in ileal digesta is therefore often undertaken using mucin carbohydrate as markers. The measurement of sialic acid in ileal digesta or excreta is used to estimate the total mucins secreted into the lumen of chicken (105), while other components including fucose, galactose, glucosamine and galactose are more commonly used in mammals (106). In chicken, sialic acid concentration in the ileal digesta was reported to be between 31.7 to $171 \mathrm{mg} / 100 \mathrm{~g}$ dry ileal digesta $(107,108)$. The observed variation in the studies may be due to the different methods in sample preparation. The mucin extraction from digesta may give a lower sialic acid concentration compared with measuring it in an intact digesta (as-is). The mucin extraction method may provide only mucin-bound sialic acids and exclude bacteria-derived sialic acids including peptidoglycans and lipopolysaccharides (109). Approximately $74 \%$ of sialic acid content in the ileal digesta of pig did not bind to the mucin subunits, while the remaining (26\%) was found as a mucin-bound form (110), thus the considerable amount of non-mucin-derived sialic acids may affect the overall sialic acid concentration in the ileal digesta. The variation in sialic acid concentration was also observed in the total tract excreta ranging from 76.5 to $148 \mathrm{mg} / 100 \mathrm{~g}$ dry excreta (111-113). Therefore, sialic acid content of the intact digesta cannot be a reliable representative for mucus loss since a major part of the measured sialic acid might be originated from bacterial cell surface (104). To gain more realistic data on the mucin loss, a further step to achieve purified crude mucin prior to carbohydrate quantification may be needed.

The endogenous proteins entering the digestive tract are predominantly originated from various digestive enzymes, mucoprotein and desquamated enterocytes. These proteins are mainly reabsorbed in the small intestine. The basal loss of endogenous amino acids in broilers (measured at the end of the ileum) was ranged from $3.08 \mathrm{~g} / \mathrm{kg}$ dry matter intake (DMI) for a protein-free diet to $8.81 \mathrm{~g} / \mathrm{kg}$ DMI for a casein diet (104). It is assumed that highly purified and digestible proteins such as casein are completely digested and absorbed in the small intestine of broilers (114) therefore, the detected amino acids at the end of the ileum of broilers fed by casein diet should be of endogenous origin. The remaining of unabsorbed endogenous proteins that passes beyond the ileum is considered as a loss of protein and energy to animal. The mucin polypeptides are relatively resistant to endogenous protease since the central mucin domains are protected by high density of $O$-glycosylation and animals do not secrete enzymes that can degrade the $O$-glycans (115). Therefore, increasing mucin secretion into the gastrointestinal tract spontaneously increases endogenous protein loss. In chicken, the amino acids of mucins are mainly composed of glutamic acid, proline, aspartic acid, threonine and serine (101). It has been reported that the mucin domains in the small intestinal of chicken are composed of proline, threonine and serine at approximately 22,29 and $30 \%$ of the total amino acid sequences, respectively (44). A study conducted on broilers, laying hens and roosters has speculated that relative comparison of proline, glutamic acid, aspartic acid, serine and threonine concentration (as the main amino acids of mucoproteins) in the ileal digesta can be used for quantitative estimation of mucoproteins contribution (mucus loss) to the ileal endogenous amino acids loss of poultry (116). To our best knowledge, a specific method for measuring the contribution of mucoproteins to ileal endogenous amino acids in poultry has not been established yet, while it has been done for other species. In pig, the contribution of mucins in digesta was determined by the regression equation of the GalNAc: GluNAc ratio of purified mucin. The amount of mucins secreted into ileal digesta accounted for $13 \%$ by weight of which, $64 \%$ was gastric mucin and $36 \%$ was intestinal mucins $(117,118)$. Although endogenous 
loss of proteins and amino acids in chickens has been widely studied, the contribution of intestinal mucins in it has not been clearly explained. In the poultry studies that have considered this matter, the contribution of intestinal mucins in the endogenous amino acids' loss has been attributed to the endogenous flow of the predominant mucin-derived amino acids.

\section{ALTERATIONS IN MUCUS PRODUCTION BY DIET AND FEEDING}

Mucus production is associated closely with the digesta and gut movements as well as bacterial enzymatic digestion. Therefore, alterations in feeding strategies and diet e.g. feed restriction, protein level, carbohydrate sources, feed form, etc., affecting nutrient digestibility and gut bacterial status (e.g. symbiosis and dysbiosis) could potentially influence the intestinal GC as well as mucins production and dynamic.

Feed restriction in chicken has been shown to alter the number and secretion of GC in the small intestine. Feed restriction after hatch reduced cell proliferation and migration rate in the small intestine resulting in decreased number of enterocytes per villus, increased GC density and reduced villus surface area $(2,119)$. Moreover, during feed restriction (24-36 hours) in newly hatched chicks, a reduction in number of GC migrating from the crypt to the villus base has been reported, causing a lesser GC number in the lower half of villus in the jejunum and ileum compared with the upper part of villus (120). On the other hand, the expression of MUC2 mRNA in the small intestine was reduced in newly hatched chickens with delayed feed access up to 72 hours, which led a decrease in mucus production $(7,120)$. This may also be considered as an indication for immature GC or/and lower total GC number in the small intestine. It has been shown that feed restriction up to 36 hours suppressed proliferation and differentiation of stem cells therefore, the number of GC in the crypt did not change (increase) and cell migration out of the crypt decreased (120). The reason for the observed increase in GC density in the villi by feed restriction could be the reduction in villus surface area (not increase in GC number per se) or boosted host defense mechanism during the delayed development of gut barrier (121). The gut barrier and immune system are generally immature in newly hatched chicks therefore, the presence of mucus is of high importance for gut protection against the invasion of pathogenic bacteria and toxins (7). Immediate feeding of hatchlings is essential and required to support the development of intestinal epithelium including enterocytes and GC, in order to strengthen mucosal barrier to prevent damages by pathogens and toxins.

A few reports showed that delayed feeding in newly hatched chicks influences mucin composition in the GC. The proportion of acidic mucins increased in 48 hours fasted newly hatched chicks compared with fed chicks $(7,122)$. The presence of acidic mucins can have a protective role against bacterial invasion because of the fact that they are less prone to degradation by bacterial enzymes (63). Thus, the reported increase in acidic mucins may be associated with reported mucosal injury and bacterial overgrowth triggered by stress and decreased intestinal movement in fasted chickens (123). However, after having access to feed, the fasted chickens showed an ability to restore cell proliferation and their GC density. The cell proliferation and migration rate can be recovered within 3-4 days after refeeding (119). The GC density in these refed chicks was similar to immediately fed chicks during the first week of age $(2,120)$.

The effects of fasting on intestinal mucus layer has been investigated in older broiler chickens. Interestingly, the amount of mucus secreted per area of intestinal tissue of growing chickens ( $>4$ weeks of age) was decreased with 72 hours feed restriction $(45,124)$, while the mucin concentrations (measured by the intensity of the bands using Western blot analysis) was increased (45). The decreased amount of mucus secreted per area might be resulted from an alteration in mucus composition especially reduction in water content, which also leads to a higher mucus concentration (125). It was proposed that the reduction in mucus secretion due to feed withdrawal in chicken may be associated with physiological regulation via cholinesterase activity (45). Mucus secretion is stimulated by acetylcholine. Feed restriction could increase acetylcholinesterase activity and subsequently decreases the stimulating signal for mucin secretion (30). In conclusion, the consequences of delayed feeding of newly hatched chicks and feed withdrawal for growing chickens is a reduction in differentiation and secretion of GC, leading to a thinner protective mucus layer and increased risk of exposure of the epithelium to luminal harmful agents. The restoration of GC population after feed introduction has been found at young age but the secretion ability of GC after feed introduction still needs to be studied further.

Dietary proteins and specific amino acids have been shown to alter mucin secretion through increasing renewal of mucus layer (126) or through providing amino acids essential for the mucin synthesis (127). Certain amino acids including threonine, proline and serine are of particular interest because of the role they play in the mucin amino acids backbone. Threonine is one of the essential amino acids which cannot be synthesized by poultry and must be provided by the diet. It was found that a reduction in dietary threonine by $60 \%$ and $30 \%$ of broiler requirement $(8.2 \mathrm{~g} /$ $\mathrm{kg}$ diet) decreased crude mucin concentration in excreta by $50 \%$ and $20 \%$. It also reduced sialic acid concentration by $49 \%$ and $9 \%$, respectively (105). Similarly, feeding a low protein diet $(19 \%$ $\mathrm{CP})$ to broilers between 21 and 42 days of age, with a decreased level of threonine, proline and serine by 4,18 and $17 \%$ respectively, caused a reduction in crude mucin excretion by $6.4-8.8 \%$ in compare with those received the standard (21\% CP) diet (128). Therefore, mucin secretion may be disturbed by deficiency of some the amino acids like threonine.

Indigestible carbohydrates have an effect on luminal components including gut microbiota, gut epithelium and mucin secretion which was discussed by Montagne et al. (106). The indigestible carbohydrates including dietary fiber (DF) play a role in regulating mucus secretion due to their properties including water-holding capacity, viscosity and abrasive surface, 
which could potentially alter the quantity, physicochemical properties and protective function of the intestinal mucus layer (105). The secretion of intestinal mucins in rat was found to be proportionally increased with increasing the volume of insoluble DF attained in water (bulk-forming properties) (129) and with the viscosity of soluble DF (130). The stimulatory effects of DF on mucin secretion could be because of an increased luminal pressure and flow resistance of bulky and viscous digesta which enhance mucus loss and GC differentiation and subsequently, increase mucin secretion (130). In chicken, several studies showed that the addition of soluble or insoluble DF stimulated GC population and mucin secretion in the small intestine (121, 131). As an example, adding either insoluble (2-4\% cellulose) or soluble fiber (2-4\% carboxymethyl cellulose) to chicken diets increased ileal GC number compared with the control group (131). Similarly, the addition of insoluble DF compound (rice hull, $100 \mathrm{~g} / \mathrm{kg}$ ) enhanced MUC2 expression, increased number of GC per villus and increased mucin secretion in the jejunum and ileum compared with the control (cornstarch) diet (121). Different types of DF sources have also been shown to increase the excretion of mucins at the terminal ileum in pigs (e.g. peas, wheat, straw, corn cobs and cellulose), rats (psyllium seed husk) and human (soya fiber) (106).

Different cereal types provide varied composition and amount of DF which could modify bacterial fermentation and their metabolic activities (132). Non-starch polysaccharides (NSP) are of high importance since they are largely indigestible in the small intestine of poultry and are mainly fermented in the hindgut by bacteria $(106,133)$. Cereals with high soluble NSP content like wheat, barley, rye and oat, can lead to a high viscous conditions in the small intestine and may alter the intestinal bacterial composition and activities compared with cereals like corn which contains lower soluble NSP $(79,134)$. The main fermentation by-products of NSP are short chain fatty acids (SCFA), predominantly acetate, propionate and butyrate. Approximately 95 to $99 \%$ of SCFA that are produced in the hindgut of non-ruminants, are absorbed and have specific roles in the body (135). As for example, acetate which is the most abundant SCFA, acts as an energy substrate for muscle tissue and can be utilized by bacteria as a precursor for butyrate synthesis. Propionate regulates glucose synthesis in liver and butyrate is used as a major source of energy for cellular metabolic activities (132). It has been shown in vitro and rat studies that SCFA, in particular butyrate, also involve in supplying energy for intestinal GC proliferation and differentiation and subsequently increase mucus production and MUC2 gene expression in the gut (136, 137). Feeding broilers with wheat/rye-based diet instead of cornbased diet increased bacterial number in the small intestine, most notably enterobacteria, and increased SCFA concentration, especially acetate and n-butyrate in the cecum (133). It also increased GC size and their number in the ileum and the cecum (134). Although soluble NSP provide the energy for bacteria which allow them to use other nutrients such as nitrogen as substrates for metabolite production, it should be concerned that the presence of these viscous-forming fibers have adverse effects on nutrient absorption. The viscous NSP can physically complex with intestinal enzymes reducing the interaction with substrates, thus decrease nutrient digestibility (133). Using SCFA as feed additives for poultry has been shown to promote intestinal development and modulate gut bacteria (138). Adding sodium butyrate $(0.8 \mathrm{~g} / \mathrm{kg})$ to broiler diets caused a distinct impact on the bacterial community and increased the number of bacteria related to the fermentation of undigested carbohydrate including Firmicutes, Bacteroidetes and Proteobacteria in the cecum and thus, further increased microbial-derived SCFA compared with the control group (138). Addition of sodium butyrate $(0.2-1 \mathrm{~g} / \mathrm{kg})$ in broiler diets increased villus length and GC density in the jejunum and ileum, and also increased mucus secretion compared with the control diet (138). Supplementing sodium butyrate $(0.5-1 \mathrm{~g} / \mathrm{kg})$ in broiler diets also increased acidic GC number per villi of the small intestine, suggesting a stimulating effect for butyrate to promote protective mechanism against mucin degradation by gut bacteria (9). In conclusion, the recent obtained data shows a potential role for dietary and bacterial SCFA specially butyrate, in regulating GC differentiation and modulating mucus production and dynamic.

The oxidative stress of the intestinal cells (e.g. colonic GC) induced by high fat diet, led to upregulation of intestinal inflammatory cytokines (e.g. IL-1b, TNF- $\alpha$ and IL-17a), along with a decrease in GC differentiation and MUC2 expression in mice (139). There is a limited information available regarding the impact of dietary fat on mucus properties in poultry. However, the intracellular fatty acid-binding proteins (FABPs) have been subject of several studies. In poultry, FABPs modulate lipid metabolism via regulation in the fatty acid uptake (in line with the concentration gradient) into the cell (140). Several FABPs including FABP1, FABP2, and FABP6 have been identified to be predominantly expressed in the digestive tract of chickens (140, 141). It has been shown that, enhancing the dietary fat level in poultry feed could increase the concentration of FABPs in the intestine (142). A downregulation in mRNA expression of FABP2 occurred in compromised gut barrier chickens (challenged with coccidiosis vaccine) along with decreased MUC2 and occludin expression, which may indicate an association between FABP2 and gut integrity in chickens (141). It was suggested that necrotic enteritis infection in broilers caused downregulation of FABP1 and FABP2 in the small intestine. These downregulations were assumed to be attributed to structural damage and intestinal epithelium loss in the small intestine and lead to reduction in fatty acid utilization (140). However, to the best of our knowledge, no direct interaction between FABPs and mucus production and/ or quality has been reported so far.A downregulation in mRNA expression of FABP2 occurred in compromised gut barrier chickens (challenged with coccidiosis vaccine) along with decreased MUC2 and occludin expression, which indicate the role of FABP2 in maintaining intestinal integrity in chicken (141). It was suggested that the downregulation of FABP1, FABP2 and other genes that are related to reduced fatty acid utilization may be also associated with intestinal inflammation and structural damage of the epithelium (140). The concentration of lipids in poultry feed is considerably lower than carbohydrates and 
proteins, but they still influence gut microbiota $(143,144)$. Feeding isoenergetic diets with different fat sources to broilers affected the $\mathrm{pH}$ and fermentation products in the ileum and cecum, which shows differences in activity and composition of the gut microbiota between these groups (144). For example, diet with palm kernel fatty acids distillers (4.3\%) increased concentration of total SCFA and lactate in the ileum and cecum and decreased digesta $\mathrm{pH}$ in the ileum compared with soybean oil (4.0\%) diet (144). As mentioned above, higher SCFA production in the gut can lead to higher GC proliferation and differentiation as well as higher mucus production $(136,137)$. Therefore, dietary fat level and type in poultry feed can have an indirect impact on intestinal integrity and mucus production. However, the extent of this impact needs further investigation.

\section{CONCLUSION AND SUGGESTIONS}

It can be concluded that the intestinal mucus layer plays an important role in maintaining the intestinal microbial balance, facilitating nutrient transport, preventing pathogen invasion, and regulating the microbial-host immune response. The intestinal mucus layer made by mucins secreted by goblet cells possesses a particular structure and molecular glycan composition for each part of the gut which contributes to its main functions including protecting itself against sheer force of dietary materials, transporting nutrient, maintaining the colonization of commensal bacteria and protecting the epithelial surfaces against pathogenic bacteria. In chicken, the considerable increase in the intestinal goblet cells density and activity in the first week of age is a response to emerging needs of newly hatched chickens for mucus secretion and immune response associated with their immediate expose to the surrounding environment and diet. The goblet cell population in the small intestine of chickens reaches maturity at 3 weeks of age. There is an anteroposterior increasing trend in the goblet cells density and mucus secretion in the small intestine of chickens which is a host adaptation to enhance protective barrier against the increasing number (and activity) of gut bacteria. Furthermore, the proximal part of the small intestine including duodenum is very active in digestion and absorption and may prioritize the proliferation of absorptive cells over goblet cells, which is associated with a lower goblet cell density, lower mucus secretion and a larger goblet cell size in the duodenum

\section{REFERENCES}

1. Birchenough GMH, Johansson MEV, Gustafsson JK, Bergström JH, Hansson GC. New Developments in Goblet Cell Mucus Secretion and Function. Mucosal Immunol (2015) 8:712-9. doi: 10.1038/mi.2015.32

2. Uni Z, Smirnov A, Sklan D. Pre- and Posthatch Development of Goblet Cells in the Broiler Small Intestine: Effect of Delayed Access to Feed. Poult Sci (2003) 82:320-7. doi: 10.1093/ps/82.2.320

3. Asai R, Okano H, Yasugi S. Correlation Between Musashi-1 and C-Hairy-1 Expression and Cell Proliferation Activity in the Developing Intestine and Stomach of Both Chicken and Mouse. Dev Growth Differ (2005) 47:501-10. doi: 10.1111/j.1440-169X.2005.00825.x compared with the jejunum and ileum. The continuous production of mucins by goblet cells mainly renews the outer mucus layer which is easily lost into the lumen by mechanical erosion and bacterial degradation. However, the regulated secretion of mucus is a rapid response to external stimuli and acts as the first defensive mechanism of the gut. The distribution of mucin types in the goblet cells is regulated by glycosylation of $O$-glycan, which can be affected by the host (e.g. inflammatory markers, hormones and neurotransmitters) and external (e.g. commensal bacteria, pathogens, pre/probiotics and nutrients in the diet) factors. Increasing in acidic mucins is known as an adaptation strategy to protect mucin from degradation by bacteria. However, several bacteria have an ability to still degrade this barrier. Any factor affecting nutrient digestibility, gut motility and digesta flow, gut bacterial status and their metabolic activity e.g. dietary factors (physical and chemical properties of feed) could potentially influence the intestinal goblet cells as well as mucin production and dynamic. The mode of action and mechanisms behind these effects need to be studied further. Mucins resist to digestive processes; therefore, a significant fraction of endogenous losses in chicken is mucins which can be considered as a loss of protein and energy to animal. Hydrothermal processing of poultry feed may reduce this loss by reduction in mucus shedding into the lumen. Given the significance of this loss and the lack of precise data about it, this matter needs to be carefully investigated in the future and the nutritional strategies reducing this loss have to be defined better.

\section{AUTHOR CONTRIBUTIONS}

Conceptualization, YD, JZ, and FGB. Writing-Original draft, YD. Writing-Review and Editing, YD, JZ, and FGB. All authors contributed to the article and approved the submitted version.

\section{ACKNOWLEDGMENTS}

The authors thank all colleagues from Holofood project for their technical support and collaboration. Holofood project has received funding from the European Union's Horizon 2020 research and innovation programme under grant agreement No 817729. Open Access Funding provided by Freie Universität Berlin.

4. Yu Y, Wang Z, Cao J, Dong Y, Wang T, Chen Y. Effects of Monochromatic Light Stimuli on the Development and Muc2 Expression of Goblet Cells in Broiler Small Intestines During Embryogenesis. Poult Sci (2014) 93:1801-8. doi: $10.3382 /$ ps.2013-03805

5. Reynolds KL, Cloft SE, Wong EA. Changes With Age in Density of Goblet Cells in the Small Intestine of Broiler Chicks. Poult Sci (2020) 99:2342-8. doi: 10.1016/j.psj.2019.12.052

6. Forder REA, Howarth GS, Tivey DR, Hughes RJ. Bacterial Modulation of Small Intestinal Goblet Cells and Mucin Composition During Early Posthatch Development of Poultry. Poult Sci (2007) 86:2396-403. doi: 10.3382/ps.2007-00222

7. Proszkowiec-Weglarz M, Schreier LL, Kahl S, Miska KB, Russell B, Elsasser TH. Effect of Delayed Feeding Post-Hatch on Expression of Tight Junction- and Gut 
Barrier-Related Genes in the Small Intestine of Broiler Chickens During Neonatal Development. Poult Sci (2020) 99:4714-29. doi: 10.1016/j.psj.2020.06.023

8. Calik A, Ergün A. Effect of Lactulose Supplementation on Growth Performance, Intestinal Histomorphology, Cecal Microbial Population, and Short-Chain Fatty Acid Composition of Broiler Chickens. Poult Sci (2015) 94:2173-82. doi: 10.3382/ps/pev182

9. Sikandar A, Zaneb H, Younus M, Masood S, Aslam A, Khattak F, et al. Effect of Sodium Butyrate on Performance, Immune Status, Microarchitecture of Small Intestinal Mucosa and Lymphoid Organs in Broiler Chickens. AsianAustralas J Anim Sci (2017) 30:690-9. doi: 10.5713/ajas.16.0824

10. Smits CHM, Te Maarssen CAA, Mouwen JMVM, Koninkx JFJG, Beynen AC. The Antinutritive Effect of a Carboxymethylcellulose With High Viscosity on Lipid Digestibility in Broiler Chickens Is Not Associated With Mucosal Damage. J Anim Physiol Anim Nutr (Berl) (2000) 83:23945. doi: 10.1046/j.1439-0396.2000.00271.x

11. Zhang Y, Liu Y, Li J, Xing T, Jiang Y, Zhang L, Gao F. Dietary Corn Resistant Starch Regulates Intestinal Morphology and Barrier Functions by Activating the Notch Signaling Pathway of Broilers. Asian-Australasian J Anim Sci (2020) 33:2008-20. doi: 10.5713/ajas.19.0967

12. Kum S, Eren U, Onol AG, Sandikci M. Effects of Dietary Organic Acid Supplementation on the Intestinal Mucosa in Broilers. Rev Med Vet (Toulouse) (2010) 161:463-8.

13. Ivkovic M, Peric L, Cvetkovic D, Glamocic D, Spring P. Effects of a Novel Carbohydrate Fraction on Broiler Performance and Intestinal Function. $S$ Afr J Anim Sci (2012) 42:131-8. doi: 10.4314/sajas.v42i2.5

14. Chen YP, Cheng YF, Li XH, Zhang H, Yang WL, Wen C, Zhou YM. Dietary Palygorskite Supplementation Improves Immunity, Oxidative Status, Intestinal Integrity, and Barrier Function of Broilers at Early Age. Anim Feed Sci Technol (2016) 219:200-9. doi: 10.1016/j.anifeedsci.2016.06.013

15. Chen YP, Cheng YF, Li XH, Yang WL, Wen C, Zhuang S, Zhou YM. Effects of Threonine Supplementation on the Growth Performance, Immunity, Oxidative Status, Intestinal Integrity, and Barrier Function of Broilers at the Early Age. Poult Sci (2017) 96:405-13. doi: 10.3382/ps/pew240

16. Khan I, Zaneb H, Masood S, Yousaf MS, Rehman HF, Rehman H. Effect of Moringa Oleifera Leaf Powder Supplementation on Growth Performance and Intestinal Morphology in Broiler Chickens. J Anim Physiol Anim Nutr (Berl) (2017) 101:114-21. doi: 10.1111/jpn.12634

17. Saleem MU, Masood S, Zaneb H, Durrani AZ, Aslam A, Ashraf K, Rehman H, Rehman M, Shaheen MS. Histophysiological Changes in Broilers Fed on Diet Supplemented With Mannanoligosaccharide and Organic Acid Blend. Pak J Zool (2018) 50:473-80. doi: 10.17582/journal.pjz/2018.50.2.473.480

18. Iji PA, Saki A, Tivey DR. Body and Intestinal Growth of Broiler Chicks on a Commercial Starter Diet. 1. Intestinal Weight and Mucosal Development. $\mathrm{Br}$ Poult Sci (2001) 42:505-13. doi: 10.1080/00071660120073151

19. Geyra A, Uni Z, Sklan D. Enterocyte Dynamics and Mucosal Development in the Posthatch Chick. Poult Sci (2001) 80:776-82. doi: 10.1093/ps/80.6.776

20. Paone P, Cani PD. Mucus Barrier, Mucins and Gut Microbiota: The Expected Slimy Partners? Gut (2020) 69:2232-43. doi: 10.1136/gutjnl-2020-322260

21. Dailey MJ. Nutrient-Induced Intestinal Adaption and its Effect in Obesity. Physiol Behav (2014) 136:74-8. doi: 10.1016/j.physbeh.2014.03.026

22. Schneider H, Pelaseyed T, Svensson F, Johansson MEV. Study of Mucin Turnover in the Small Intestine by In Vivo Labeling. Sci Rep (2018) 8:5760. doi: $10.1038 / s 41598-018-24148-x$

23. Smirnov A, Perez R, Amit-Romach E, Sklan D, Uni Z. Mucin Dynamics and Microbial Populations in Chicken Small Intestine Are Changed by Dietary Probiotic and Antibiotic Growth Promoter Supplementation. J Nutr (2005) 135:187-92. doi: 10.1093/jn/135.2.187

24. Svihus B, Itani K. Intestinal Passage and Its Relation to Digestive Processes. J Appl Poult Res (2019) 28:546-55. doi: 10.3382/japr/pfy027

25. Kim YS, Ho SB. Intestinal Goblet Cells and Mucins in Health and Disease: Recent Insights and Progress. Curr Gastroenterol Rep (2010) 12:319-30. doi: 10.1007/s11894-010-0131-2

26. Bar Shira E, Friedman A. Innate Immune Functions of Avian Intestinal Epithelial Cells: Response to Bacterial Stimuli and Localization of Responding Cells in the Developing Avian Digestive Tract. PLoS One (2018) 13:e0200393. doi: 10.1371/journal.pone.0200393

27. Kim J, Khan WI. Goblet Cells and Mucins: Role in Innate Defense in Enteric Infections. Pathogens (2013) 2:55-70. doi: 10.3390/pathogens2010055
28. Collier CT, Hofacre CL, Payne AM, Anderson DB, Kaiser P, Mackie RI, et al. Coccidia-Induced Mucogenesis Promotes the Onset of Necrotic Enteritis by Supporting Clostridium Perfringens Growth. Vet Immunol Immunopathol (2008) 122:104-15. doi: 10.1016/j.vetimm.2007.10.014

29. Specian RD, Neutra MR. Cytoskeleton of Intestinal Goblet Cells in Rabbit and Monkey. Gastroenterology (1984) 87:1313-25. doi: 10.1016/0016-5085 (84) $90198-7$

30. Leparoux S, Sine J-P, Ferrand R, Colas B. Behaviour of Butyrylcholinesterase in the Intestinal Epithelial Cells of Starved and Refed Rats. Int J Biochem (1992) 24:263-6. doi: 10.1016/0020-711X(92)90256-Z

31. Gustafsson JK, Ermund A, Johansson MEV, Schütte A, Hansson GC, Sjövall H. An Ex Vivo Method for Studying Mucus Formation, Properties, and Thickness in Human Colonic Biopsies and Mouse Small and Large Intestinal Explants. Am J Physiol - Gastrointest Liver Physiol (2012) 302:430-8. doi: 10.1152/ajpgi.00405.2011

32. McGuckin MA, Lindén SK, Sutton P, Florin TH. Mucin Dynamics and Enteric Pathogens. Nat Rev Microbiol (2011) 9:265-78. doi: 10.1038/ nrmicro2538

33. Cheled-Shoval SL, Gamage NSW, Amit-Romach E, Forder R, Marshal J, Van Kessel A, et al. Differences in Intestinal Mucin Dynamics Between GermFree and Conventionally Reared Chickens After Mannan-Oligosaccharide Supplementation. Poult Sci (2014) 93:636-44. doi: 10.3382/ps.2013-03362

34. Wang L, Li J, Li J, Li RX, Lv CF, Li S, et al. Identification of the Paneth Cells in Chicken Small Intestine. Poult Sci (2016) 95:1631-5. doi: 10.3382/PS/PEW079

35. Nile CJ, Townes CL, Michailidis G, Hirst BH, Hall J. Identification of Chicken Lysozyme G2 and its Expression in the Intestine. Cell Mol Life Sci C 20046121 (2004) 61:2760-6. doi: 10.1007/S00018-004-4345-Z

36. Park CM, Reid PE, Owen DA, Volz D, Dunn WL. Histochemical Studies of Epithelial Cell Glycoproteins in Normal Rat Colon. Histochem J (1987) 19:546-54. doi: 10.1007/BF01687362

37. Birchenough GMH, Nystrom EEL, Johansson MEV, Hansson GC. A Sentinel Goblet Cell Guards the Colonic Crypt by Triggering Nlrp6Dependent Muc2 Secretion. Science (80-) (2016) 352:1535-42. doi: 10.1126/science.aaf7419

38. Elo HA, Kulomaa MS, Tuohimaa PJ. Avidin Induction by Tissue Injury and Inflammation in Male and Female Chickens. Comp Biochem Physiol Part B Comp Biochem (1979) 62:237-40. doi: 10.1016/0305-0491(79)90205-0

39. Rychlik I, Elsheimer-Matulova M, Kyrova K, Gene KK. Gene Expression in the Chicken Caecum in Response to Infections With Non-Typhoid Salmonella. Vet Res (2014) 45:119. doi: 10.1186/s13567-014-0119-2i

40. Hurley WL, Theil PK. Perspectives on Immunoglobulins in Colostrum and Milk. Nutr (2011) 3:442-74. doi: 10.3390/NU3040442

41. Bar-Shira E, Cohen I, Elad O, Friedman A. Role of Goblet Cells and Mucin Layer in Protecting Maternal IgA in Precocious Birds. Dev Comp Immunol (2014) 44:186-94. doi: 10.1016/j.dci.2013.12.010

42. Montagne L, Piel C, Lallès JP. Effect of Diet on Mucin Kinetics and Composition: Nutrition and Health Implications. Nutr Rev (2004) 62:10514. doi: 10.1301/nr.2004.mar.105-114

43. MacMillan JL, Vicaretti SD, Noyovitz B, Xing X, Low KE, Inglis GD, et al. Structural Analysis of Broiler Chicken Small Intestinal Mucin O-Glycan Modification by Clostridium Perfringens. Poult Sci (2019) 98:5074-88. doi: $10.3382 / \mathrm{ps} / \mathrm{pez} 297$

44. Jiang Z, Applegate TJ, Lossie AC. Cloning, Annotation and Developmental Expression of the Chicken Intestinal MUC2 Gene. PLoS One (2013) 8: e53781. doi: 10.1371/journal.pone.0053781

45. Smirnov A, Sklan D, Uni Z. Mucin Dynamics in the Chick Small Intestine Are Altered by Starvation. J Nutr (2004) 134:736-42. doi: 10.1093/jn/ 134.4.736

46. Tsirtsikos P, Fegeros K, Balaskas C, Kominakis A, Mountzouris KC. Dietary Probiotic Inclusion Level Modulates Intestinal Mucin Composition and Mucosal Morphology in Broilers. Poult Sci (2012) 91:1860-8. doi: 10.3382/ ps.2011-02005

47. Tsirtsikos P, Fegeros K, Kominakis A, Balaskas C, Mountzouris KC Modulation of Intestinal Mucin Composition and Mucosal Morphology by Dietary Phytogenic Inclusion Level in Broilers. Animal (2012) 6:1049-57. doi: $10.1017 / S 1751731111002680$

48. Antonissen G, Van Immerseel F, Pasmans F, Ducatelle R, Janssens GPJ, De Baere S, et al. Mycotoxins Deoxynivalenol and Fumonisins Alter the 
Extrinsic Component of Intestinal Barrier in Broiler Chickens. J Agric Food Chem (2015) 63:10846-55. doi: 10.1021/acs.jafc.5b04119

49. Macierzanka A, Rigby NM, Corfield AP, Wellner N, Böttger F, Mills ENC, et al. Adsorption of Bile Salts to Particles Allows Penetration of Intestinal Mucus. Soft Matter (2011) 7:8077. doi: 10.1039/c1sm05888f

50. Derrien M, van Passel MWJ, van de Bovenkamp JHB, Schipper RG, de Vos WM, Dekker J. Mucin-Bacterial Interactions in the Human Oral Cavity and Digestive Tract. Gut Microbes (2010) 1:254-68. doi: 10.4161/gmic.1.4.12778

51. Osho SO, Wang T, Horn NL, Adeola O. Comparison of Intestinal Goblet Cell Staining Methods in Turkey Poults. J Anim Sci (2017) 96:556-9. doi: 10.2527/jam2016-0439

52. Roberton AM, Wright DP. Bacterial Glycosulphatases and Sulphomucin Degradation. Can J Gastroenterol (1997) 11:361-6. doi: 10.1155/1997/ 642360

53. Wils-Plotz EL, Dilger RN. Combined Dietary Effects of Supplemental Threonine and Purified Fiber on Growth Performance and Intestinal Health of Young Chicks. Poult Sci (2013) 92:726-34. doi: 10.3382/ps.201202664

54. Chee SH, Iji PA, Choct M, Mikkelsen LL, Kocher A. Functional Interactions of Manno-Oligosaccharides With Dietary Threonine in Chicken Gastrointestinal Tract. I. Growth Performance and Mucin Dynamics. $\mathrm{Br}$ Poult Sci (2010) 51:658-66. doi: 10.1080/00071668.2010.517251

55. Faderl M, Noti M, Corazza N, Mueller C. Keeping Bugs in Check: The Mucus Layer as a Critical Component in Maintaining Intestinal Homeostasis. IUBMB Life (2015) 67:275-85. doi: 10.1002/iub.1374

56. Johansson MEV, Sjövall H, Hansson GC. The Gastrointestinal Mucus System in Health and Disease. Nat Rev Gastroenterol Hepatol (2013) 10:352-61. doi: 10.1038/nrgastro.2013.35

57. Schütte A, Ermund A, Becker-Pauly C, Johansson MEV, Rodriguez-Pineiro AM, Bac̈khed F, et al. Microbial-Induced Meprin $\beta$ Cleavage in MUC2 Mucin and a Functional CFTR Channel are Required to Release Anchored Small Intestinal Mucus. Proc Natl Acad Sci U S A (2014) 111:12396-401. doi: $10.1073 /$ pnas. 1407597111

58. Corfield AP. Mucins in the Gastrointestinal Tract in Health and Disease. Front Biosci (2001) 6:A684. doi: 10.2741/A684

59. Forder REA, Nattrass GS, Geier MS, Hughes RJ, Hynd PI. Quantitative Analyses of Genes Associated With Mucin Synthesis of Broiler Chickens With Induced Necrotic Enteritis. Poult Sci (2012) 91:1335-41. doi: 10.3382/ ps.2011-02062

60. Lang T, Hansson GC, Samuelsson T. An Inventory of Mucin Genes in the Chicken Genome Shows That the Mucin Domain of Muc13 is Encoded by Multiple Exons and That Ovomucin is Part of a Locus of Related Gel-Forming Mucins. BMC Genomics (2006) 7:197. doi: 10.1186/1471-2164-7-197

61. Bäckström M, Ambort D, Thomsson E, Johansson MEV, Hansson GC. Increased Understanding of the Biochemistry and Biosynthesis of MUC2 and Other Gel-Forming Mucins Through the Recombinant Expression of Their Protein Domains. Mol Biotechnol (2013) 54:250-6. doi: 10.1007/ s12033-012-9562-3

62. Herath M, Hosie S, Bornstein JC, Franks AE, Hill-Yardin EL. The Role of the Gastrointestinal Mucus System in Intestinal Homeostasis: Implications for Neurological Disorders. Front Cell Infect Microbiol (2020) 10:248. doi: $10.3389 /$ fcimb. 2020.00248

63. Hino S, Takemura N, Sonoyama K, Morita A, Kawagishi H, Aoe S, et al. Small Intestinal Goblet Cell Proliferation Induced by Ingestion of Soluble and Insoluble Dietary Fiber Is Characterized by An Increase in Sialylated Mucins in Rats. J Nutr (2012) 142:1429-36. doi: 10.3945/jn.112.159731

64. Smirnov A, Tako E, Ferket PR, Uni Z. Mucin Gene Expression and Mucin Content in the Chicken Intestinal Goblet Cells Are Affected by In Ovo Feeding of Carbohydrates. Poult Sci (2006) 85:669-73. doi: 10.1093/ps/85.4.669

65. Golder HM, Geier MS, Forder REA, Hynd PI, Hughes RJ. Effects of Necrotic Enteritis Challenge on Intestinal Micro-Architecture and Mucin Profile. $\mathrm{Br}$ Poult Sci (2011) 52:500-6. doi: 10.1080/00071668.2011.587183

66. Allen A, Flemström G. Gastroduodenal Mucus Bicarbonate Barrier: Protection Against Acid and Pepsin. Am J Physiol Physiol (2005) 288:C119. doi: 10.1152/ajpcell.00102.2004

67. Strugala V, Allen A, Dettmar PW, Pearson JP. Colonic Mucin: Methods of Measuring Mucus Thickness. Proc Nutr Soc (2003) 62:237-43. doi: 10.1079/ pns2002205
68. Atuma C, Strugala V, Allen A, Holm L. The Adherent Gastrointestinal Mucus Gel Layer: Thickness and Physical State In Vivo. Am J Physiol Liver Physiol (2001) 280:G922-9. doi: 10.1152/ajpgi.2001.280.5.G922

69. Keely S, Feighery L, Campion DP, O’Brien L, Brayden DJ, Baird AW. Chloride-Led Disruption of the Intestinal Mucous Layer Impedes Salmonella Invasion: Evidence for an 'Enteric Tear' Mechanism. Cell Physiol Biochem (2011) 28:743-52. doi: 10.1159/000335768

70. Ermund A, Schütte A, Johansson MEV, Gustafsson JK, Hansson GC. Studies of Mucus in Mouse Stomach, Small Intestine, and Colon. I. Gastrointestinal Mucus Layers Have Different Properties Depending on Location as Well as Over the Peyer's Patches. Am J Physiol Liver Physiol (2013) 305:G341-7. doi: 10.1152/ajpgi.00046.2013

71. Ensign LM, Henning A, Schneider CS, Maisel K, Wang YY, Porosoff MD, et al. Ex Vivo Characterization of Particle Transport in Mucus Secretions Coating Freshly Excised Mucosal Tissues. Mol Pharm (2013) 10:2176-82. doi: $10.1021 / \mathrm{mp} 400087 \mathrm{y}$

72. Leal J, Smyth HDC, Ghosh D. Physicochemical Properties of Mucus and Their Impact on Transmucosal Drug Delivery. Int J Pharm (2017) 532:55572. doi: 10.1016/j.ijpharm.2017.09.018

73. Macierzanka A, Mackie AR, Krupa L. Permeability of the Small Intestinal Mucus for Physiologically Relevant Studies: Impact of Mucus Location and Ex Vivo Treatment. Sci Rep (2019) 9:1-10. doi: 10.1038/s41598-019-53933-5

74. Lieleg O, Vladescu I, Ribbeck K. Characterization of Particle Translocation Through Mucin Hydrogels. Biophys J (2010) 98:1782-9. doi: 10.1016/ j.bpj.2010.01.012

75. Li LD, Crouzier T, Sarkar A, Dunphy L, Han J, Ribbeck K. Spatial Configuration and Composition of Charge Modulates Transport Into a Mucin Hydrogel Barrier. Biophys J (2013) 105:1357-65. doi: 10.1016/ j.bpj.2013.07.050

76. Ravindran V. Feed Enzymes: The Science, Practice, and Metabolic Realities. J Appl Poult Res (2013) 22:628-36. doi: 10.3382/japr.2013-00739

77. Lai SK, Wang Y-Y, Wirtz D, Hanes J. Micro-And Macrorheology of Mucus. Adv Drug Deliv Rev (2009) 61:86-100. doi: 10.1016/j.addr.2008.09.012

78. Fuchs A, Dressman JB. Composition and Physicochemical Properties of Fasted-State Human Duodenal and Jejunal Fluid: A Critical Evaluation of the Available Data. J Pharm Sci (2014) 103:3398-411. doi: 10.1002/jps.24183

79. Rehman HU, Vahjen W, Awad WA, Zentek J. Indigenous Bacteria and Bacterial Metabolic Products in the Gastrointestinal Tract of Broiler Chickens. Arch Anim Nutr (2007) 61:319-35. doi: 10.1080/ 17450390701556817

80. Rinttilä T, Apajalahti J. Intestinal Microbiota and Metabolites-Implications for Broiler Chicken Health and Performance. J Appl Poult Res (2013) 22:647-58. doi: 10.3382/japr.2013-00742

81. Kurokawa K, Itoh T, Kuwahara T, Oshima K, Toh H, Toyoda A, et al. Comparative Metagenomics Revealed Commonly Enriched Gene Sets in Human Gut Microbiomes. DNA Res (2007) 14:169-81. doi: 10.1093/dnares/ dsm018

82. Josenhans C, Müthing J, Elling L, Bartfeld S, Schmidt H. How Bacterial Pathogens of the Gastrointestinal Tract Use the Mucosal Glyco-Code to Harness Mucus and Microbiota: New Ways to Study an Ancient Bag of Tricks. Int J Med Microbiol (2020) 310:151392. doi: 10.1016/ j.ijmm.2020.151392

83. Sicard JF, Le Bihan G, Vogeleer P, Jacques M, Harel J. Interactions of Intestinal Bacteria With Components of the Intestinal Mucus. Front Cell Infect Microbiol (2017) 7:387. doi: 10.3389/fcimb.2017.00387

84. Struwe WB, Gough R, Gallagher ME, Kenny DT, Carrington SD, Karlsson NG, et al. Identification of O-Glycan Structures From Chicken Intestinal Mucins Provides Insight Into Campylobactor Jejuni Pathogenicity*. Mol Cell Proteomics (2015) 14:1464-77. doi: 10.1074/mcp.M114.044867

85. Carniello V, Peterson BW, van der Mei HC, Busscher HJ. PhysicoChemistry From Initial Bacterial Adhesion to Surface-Programmed Biofilm Growth. Adv Colloid Interface Sci (2018) 261:1-14. doi: 10.1016/ j.cis.2018.10.005

86. Tailford LE, Crost EH, Kavanaugh D, Juge N. Mucin Glycan Foraging in the Human Gut Microbiome. Front Genet (2015) 5:81. doi: 10.3389/ fgene.2015.00081

87. Ashida H, Maki R, Ozawa H, Tani Y, Kiyohara M, Fujita M, et al. Characterization of Two Different Endo- $\alpha$-N-Acetylgalactosaminidases 
From Probiotic and Pathogenic Enterobacteria, Bifidobacterium Longum and Clostridium Perfringens. Glycobiology (2008) 18:727-34. doi: 10.1093/ glycob/cwn053

88. Robinson LS, Lewis WG, Lewis AL. The Sialate O-Acetylesterase EstA From Gut Bacteroidetes Species Enables Sialidase-Mediated Cross-Species Foraging of 9-O-Acetylated Sialoglycans. J Biol Chem (2017) 292:1186172. doi: $10.1074 /$ jbc.M1 16.769232

89. Sacranie A, Svihus B, Denstadli V, Moen B, Iji PA, Choct M. The Effect of Insoluble Fiber and Intermittent Feeding on Gizzard Development, Gut Motility, and Performance of Broiler Chickens. Poult Sci (2012) 91:693-700. doi: 10.3382/ps.2011-01790

90. Zentek J, Goodarzi Boroojeni F. (Bio)Technological Processing of Poultry and Pig Feed: Impact on the Composition, Digestibility, Anti-Nutritional Factors and Hygiene. Anim Feed Sci Technol (2020) 268:114576. doi: 10.1016/j.anifeedsci.2020.114576

91. Goodarzi Boroojeni F, Svihus B, Graf von Reichenbach H, Zentek J. The Effects of Hydrothermal Processing on Feed Hygiene, Nutrient Availability, Intestinal Microbiota and Morphology in Poultry-A Review. Anim Feed Sci Technol (2016) 220:187-215. doi: 10.1016/j.anifeedsci.2016.07.010

92. Mohammadi Ghasem Abadi MH, Moravej H, Shivazad M, Karimi Torshizi MA, Kim WK. Effects of Feed Form and Particle Size, and Pellet Binder on Performance, Digestive Tract Parameters, Intestinal Morphology, and Cecal Microflora Populations in Broilers. Poult Sci (2019) 98:1432-40. doi: $10.3382 / \mathrm{ps} /$ pey 488

93. Ruhnke I, Röhe I, Krämer C, Goodarzi Boroojeni F, Knorr F, Mader A, et al. The Effects of Particle Size, Milling Method, and Thermal Treatment of Feed on Performance, Apparent Ileal Digestibility, and $\mathrm{pH}$ of the Digesta in Laying Hens. Poult Sci (2014) 94:692-9. doi: 10.3382/ps/pev030

94. Pacheco WJ, Stark CR, Ferket PR, Brake J. Evaluation of Soybean Meal Source and Particle Size on Broiler Performance, Nutrient Digestibility, and Gizzard Development. Poult Sci (2013) 92:2914-22. doi: 10.3382/ps.2013-03186

95. Siegert W, Ganzer C, Kluth H, Rodehutscord M. Effect of Particle Size Distribution of Maize and Soybean Meal on the Precaecal Amino Acid Digestibility in Broiler Chickens. Br Poult Sci (2018) 59:68-75. doi: 10.1080/ 00071668.2017.1380295

96. Zang JJ, Piao XS, Huang DS, Wang JJ, Ma X, Ma YX. Effects of Feed Particle Size and Feed Form on Growth Performance, Nutrient Metabolizability and Intestinal Morphology in Broiler Chickens. Asian-Australas J Anim Sci (2009) 22:107-12. doi: 10.5713/ajas.2009.80352

97. Parsons AS, Buchanan NP, Blemings KP, Wilson ME, Moritz JS. Effect of Corn Particle Size and Pellet Texture on Broiler Performance in the Growing Phase. J Appl Poult Res (2006) 15:245-55. doi: 10.1093/japr/15.2.245

98. Svihus B. Function of the Digestive System. J Appl Poult Res (2014) 23:30614. doi: 10.3382/japr.2014-00937

99. Hetland H, Svihus B, Krogdahl Å. Effects of Oat Hulls and Wood Shavings on Digestion in Broilers and Layers Fed Diets Based on Whole or Ground Wheat. Br Poult Sci (2003) 44:275-82. doi: 10.1080/0007166031000124595

100. Xu Y, Stark CR, Ferket PR, Williams CM, Pacheco WJ, Brake J. Effect of Dietary Coarsely Ground Corn on Broiler Live Performance, Gastrointestinal Tract Development, Apparent Ileal Digestibility of Energy and Nitrogen, and Digesta Particle Size Distribution and Retention Time. Poult Sci (2015) 94:53-60. doi: 10.3382/ps/peu015

101. Adedokun SA, Adeola O, Parsons CM, Lilburn MS, Applegate TJ. Factors Affecting Endogenous Amino Acid Flow in Chickens and the Need for Consistency in Methodology. Poult Sci (2011) 90:1737-48. doi: 10.3382/ ps.2010-01245

102. Chang M, Alsaigh T, Kistler EB, Schmid-Schönbein GW. Breakdown of Mucin as Barrier to Digestive Enzymes in the Ischemic Rat Small Intestine. PLoS One (2012) 7:e40087. doi: 10.1371/journal.pone.0040087

103. Miner-Williams WM, Moughan PJ, Fuller MF. Analysis of an Ethanol Precipitate From Ileal Digesta: Evaluation of a Method to Determine Mucin. Sci Rep (2013) 3:1-6. doi: 10.1038/srep03145

104. Ravindran V. Progress in Ileal Endogenous Amino Acid Flow Research in Poultry. J Anim Sci Biotechnol (2021) 12:1-11. doi: 10.1186/s40104-02000526-2

105. Horn NL, Donkin SS, Applegate TJ, Adeola O. Intestinal Mucin Dynamics: Response of Broiler Chicks and White Pekin Ducklings to Dietary Threonine. Poult Sci (2009) 88:1906-14. doi: 10.3382/ps.2009-00009
106. Montagne L, Pluske J. Hampson D. A Review of Interactions Between Dietary Fibre and the Intestinal Mucosa, and Their Consequences on Digestive Health in Young non-Ruminant Animals. Anim Feed Sci Technol (2003) 108:95-117. doi: 10.1016/S0377-8401(03)00163-9

107. Chamorro S, Romero C, Brenes A, Sánchez-Patán F, Bartolomé B, Viveros A, et al. Impact of a Sustained Consumption of Grape Extract on Digestion, Gut Microbial Metabolism and Intestinal Barrier in Broiler Chickens. Food Funct (2019) 10:1444-54. doi: 10.1039/C8FO02465K

108. Cowieson AJ, Abdollahi MR, Zaefarian F, Pappenberger G, Ravindran V. The Effect of a Mono-Component Exogenous Protease and Graded Concentrations of Ascorbic Acid on the Performance, Nutrient Digestibility and Intestinal Architecture of Broiler Chickens. Anim Feed Sci Technol (2018) 235:128-37. doi: 10.1016/j.anifeedsci.2017.11.018

109. Han Z, Thuy-Boun PS, Pfeiffer W, Vartabedian VF, Torkamani A, Teijaro JR, et al. Identification of an N-Acetylneuraminic Acid-Presenting Bacteria Isolated From a Human Microbiome. Sci Rep (2021) 11:4763. doi: 10.1038/ s41598-021-83875-w

110. Miner-Williams W, Moughan PJ, Fuller MF. Methods for Mucin Analysis: A Comparative Study. J Agric Food Chem (2009) 57:6029-35. doi: 10.1021/jf901036r

111. Abdulla JM, Rose SP, Mackenzie AM, Ivanova SG, Staykova GP, Pirgozliev VR. Nutritional Value of Raw and Micronised Field Beans ( Vicia Faba L. Var. Minor ) With and Without Enzyme Supplementation Containing Tannase for Growing Chickens. Arch Anim Nutr (2016) 70:350-63. doi: 10.1080/1745039X.2016.1214344

112. Pirgozliev V, Bravo D, Mirza MW, Rose SP. Growth Performance and Endogenous Losses of Broilers Fed Wheat-Based Diets With and Without Essential Oils and Xylanase Supplementation. Poult Sci (2015) 94:1227-32. doi: $10.3382 / \mathrm{ps} / \mathrm{peu} 017$

113. Pirgozliev V, Brearley CA, Rose SP, Mansbridge SC. Manipulation of Plasma Myo-Inositol in Broiler Chickens: Effect on Growth Performance, Dietary Energy, Nutrient Availability, and Hepatic Function. Poult Sci (2019) 98:260-8. doi: 10.3382/ps/pey341

114. Adeola O, Xue PC, Cowieson AJ, Ajuwon KM. Basal Endogenous Losses of Amino Acids in Protein Nutrition Research for Swine and Poultry. Anim Feed Sci Technol (2016) 221:274-83. doi: 10.1016/j.anifeedsci.2016.06.004

115. Rodríguez-Piñeiro AM, Bergström JH, Ermund A, Gustafsson JK, Schütte A, Johansson MEV, et al. Studies of Mucus in Mouse Stomach, Small Intestine, and Colon. II. Gastrointestinal Mucus Proteome Reveals Muc2 and Muc5ac Accompanied by a Set of Core Proteins. Am J Physiol - Gastrointest Liver Physiol (2013) 305:348-56. doi: 10.1152/ajpgi.00047.2013

116. Ravindran V, Hendriks WH. Endogenous Amino Acid Flows at the Terminal Ileum of Broilers, Layers and Adult Roosters. Anim Sci (2004) 79:265-71. doi: 10.1017/S1357729800090123

117. Miner-Williams W, Moughan PJ, Fuller MF. Endogenous Components of Digesta Protein From the Terminal Ileum of Pigs Fed a Casein-Based Diet. J Agric Food Chem (2009) 57:2072-8. doi: 10.1021/jf8023886

118. Lien KA, Sauer WC, Fenton M. Mucin Output in Ileal Digesta of Pigs Fed a Protein-Free Diet. Z Ernahrungswiss (1997) 36:182-90. doi: 10.1007/BF01611398

119. Geyra A, Uni Z, Sklan D. The Effect of Fasting at Different Ages on Growth and Tissue Dynamics in the Small Intestine of the Young Chick. Br J Nutr (2001) 86:53-61. doi: 10.1079/bjn2001368

120. Liu K, Jia M, Wong EA. Delayed Access to Feed Affects Broiler Small Intestinal Morphology and Goblet Cell Ontogeny. Poult Sci (2020) 99:527585. doi: $10.1016 /$ j.psj.2020.07.040

121. Murai A, Kitahara K, Terada H, Ueno A, Ohmori Y, Kobayashi M, et al. Ingestion of Paddy Rice Increases Intestinal Mucin Secretion and Goblet Cell Number and Prevents Dextran Sodium Sulfate-Induced Intestinal Barrier Defect in Chickens. Poult Sci (2018) 97:3577-86. doi: 10.3382/ps/pey202

122. Uni Z, Tako E, Gal-Garber O, Sklan D. Morphological, Molecular, and Functional Changes in the Chicken Small Intestine of the Late-Term Embryo. Poult Sci (2003) 82:1747-54. doi: 10.1093/ps/82.11.1747

123. Zhou QQ, Yang DZ, Luo YJ, Li SZ, Liu FY, Wang GS. Over-Starvation Aggravates Intestinal Injury and Promotes Bacterial and Endotoxin Translocation Under High-Altitude Hypoxic Environment. World J Gastroenterol (2011) 17:1584-93. doi: 10.3748/wjg.v17.i12.1584

124. Thompson KL, Applegate TJ. Feed Withdrawal Alters Small-Intestinal Morphology and Mucus of Broilers. Poult Sci (2006) 85:1535-40. doi: $10.1093 / \mathrm{ps} / 85.9 .1535$ 
125. Steiner M, Bourges H, Freedman L, Gray S. Effect of Starvation on the Tissue Composition of the Small Intestine in the Rat. Am J Physiol Content (1968) 215:75-7. doi: 10.1152/ajplegacy.1968.215.1.75

126. Ravindran V, Morel PCH, Rutherfurd SM, Thomas DV. Endogenous Flow of Amino Acids in the Avian Ileum as Influenced by Increasing Dietary Peptide Concentrations. Br J Nutr (2008) 101:822-8. doi: 10.1017/S0007114508039974

127. Visscher C, Klingenberg L, Hankel J, Brehm R, Langeheine M, Helmbrecht A. Feed Choice Led to Higher Protein Intake in Broiler Chickens Experimentally Infected With Campylobacter Jejuni. Front Nutr (2018) 5:79. doi: 10.3389/fnut.2018.00079

128. Visscher C, Klingenberg L, Hankel J, Brehm R, Langeheine M, Helmbrecht A. Influence of a Specific Amino Acid Pattern in the Diet on the Course of an Experimental Campylobacter Jejuni Infection in Broilers. Poult Sci (2018) 97:4020-30. doi: 10.3382/ps/pey276

129. Tanabe H, Sugiyama K, Matsuda T, Kiriyama S, Morita T. Small Intestinal Mucins are Secreted in Proportion to the Settling Volume in Water of Dietary Indigestible Components in Rats. J Nutr (2005) 135:2431-7. doi: $10.1093 /$ jn/135.10.2431

130. Ito H, Satsukawa M, Arai E, Sugiyama K, Sonoyama K, Kiriyama S, et al. Soluble Fiber Viscosity Affects Both Goblet Cell Number and Small Intestine Mucin Secretion in Rats. J Nutr (2009) 139:1640-7. doi: 10.3945/jn.109.110171

131. Rahmatnejad E, Saki AA. Effect of Dietary Fibres on Small Intestine Histomorphology and Lipid Metabolism in Young Broiler Chickens. J Anim Physiol Anim Nutr (Berl) (2016) 100:665-72. doi: 10.1111/jpn.12422

132. Kouzounis D, Hageman JA, Soares N, Michiels J, Schols HA. Impact of Xylanase and Glucanase on Oligosaccharide Formation, Carbohydrate Fermentation Patterns, and Nutrient Utilization in the Gastrointestinal Tract of Broilers. Animals (2021) 11:1285. doi: 10.3390/ani11051285

133. Hübener K, Vahjen W, Simon O. Bacterial Responses to Different Dietary Cereal Types and Xylanase Supplementation in the Intestine of Broiler Chicken. Arch Anim Nutr fur Tierernahr (2002) 56:167-87. doi: 10.1080/ 00039420214191

134. Teirlynck E, Bjerrum L, Eeckhaut V, Huygebaert G, Pasmans F, Haesebrouck F, et al. Immerseel F Van. The Cereal Type in Feed Influences Gut Wall Morphology and Intestinal Immune Cell Infiltration in Broiler Chickens. $\mathrm{Br} J$ Nutr (2009) 102:1453-61. doi: 10.1017/S0007114509990407

135. von Engelhardt W, Bartels J, Kirschberger S, zu Düttingdorf HDM, Busche R. Role of Short-Chain Fatty Acids in the Hind Gut. Vet Q (1998) 20:52-9. doi: 10.1080/01652176.1998.9694970

136. Burger-van Paassen N, Vincent A, Puiman PJJ, van der Sluis M, Bouma J, Boehm G, et al. The Regulation of Intestinal Mucin MUC2 Expression by Short-Chain Fatty Acids: Implications for Epithelial Protection. Biochem J (2009) 420:211-9. doi: 10.1042/BJ20082222

137. Wrzosek L, Miquel S, Noordine ML, Bouet S, Chevalier-Curt MJ, Robert V, et al. Bacteroides Thetaiotaomicron and Faecalibacterium Prausnitzii
Influence the Production of Mucus Glycans and the Development of Goblet Cells in the Colonic Epithelium of a Gnotobiotic Model Rodent. BMC Biol (2013) 11:1-13. doi: 10.1186/1741-7007-11-61

138. Wu W, Xiao Z, An W, Dong Y, Zhang B. Dietary Sodium Butyrate Improves Intestinal Development and Function by Modulating the Microbial Community in Broilers. PLoS One (2018) 13:1-21. doi: 10.1371/ journal.pone.0197762

139. Gulhane M, Murray L, Lourie R, Tong H, Sheng YH, Wang R, et al. High Fat Diets Induce Colonic Epithelial Cell Stress and Inflammation That is Reversed by IL-22. Sci Rep (2016) 6:1-17. doi: 10.1038/SREP28990

140. Gharib-Naseri K, de Las Heras-Saldana S, Kheravii S, Qin L, Wang J, Wu SB. Necrotic Enteritis Challenge Regulates Peroxisome Proliferator-1 Activated Receptors Signaling and $\beta$-Oxidation Pathways in Broiler Chickens. Anim Nutr (2021) 7:239-51. doi: 10.1016/J.ANINU.2020.08.003

141. Chen J, Tellez G, Richards JD, Escobar J. Identification of Potential Biomarkers for Gut Barrier Failure in Broiler Chickens. Front Vet Sci (2015) 2:1-10. doi: 10.3389/fvets.2015.00014

142. Katongole JB, March BE. Fatty Acid Binding Protein in the Intestine of the Chicken. Poult Sci (1979) 58:372-5. doi: 10.3382/PS.0580372

143. Just S, Mondot S, Ecker J, Wegner K, Rath E, Gau L, et al. The Gut Microbiota Drives the Impact of Bile Acids and Fat Source in Diet on Mouse Metabolism. Microbiome (2018) 6:1-18. doi: 10.1186/s40168-0180510-8

144. Józefiak D, Kierończyk B, Rawski M, Hejdysz M, Rutkowski A, Engberg RM, et al. Clostridium Perfringens Challenge and Dietary Fat Type Affect Broiler Chicken Performance and Fermentation in the Gastrointestinal Tract. Animal (2014) 8:912-22. doi: 10.1017/S1751731114000536

Conflict of Interest: The authors declare that the research was conducted in the absence of any commercial or financial relationships that could be construed as a potential conflict of interest.

Publisher's Note: All claims expressed in this article are solely those of the authors and do not necessarily represent those of their affiliated organizations, or those of the publisher, the editors and the reviewers. Any product that may be evaluated in this article, or claim that may be made by its manufacturer, is not guaranteed or endorsed by the publisher.

Copyright (c) 2021 Duangnumsawang, Zentek and Goodarzi Boroojeni. This is an open-access article distributed under the terms of the Creative Commons Attribution License (CC BY). The use, distribution or reproduction in other forums is permitted, provided the original author(s) and the copyright owner(s) are credited and that the original publication in this journal is cited, in accordance with accepted academic practice. No use, distribution or reproduction is permitted which does not comply with these terms. 